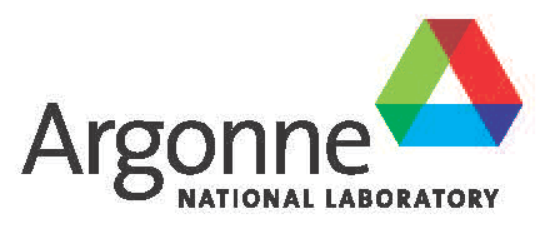

\title{
Developing Surrogate Far-Field Nuclear Fallout and Its Rapid Decontamination from Aircraft Surfaces
}

Strategic Security Sciences Division 


\begin{abstract}
About Argonne National Laboratory
Argonne is a U.S. Department of Energy laboratory managed by UChicago Argonne, LLC under contract DE-AC02-06CH11357. The Laboratory's main facility is outside Chicago, at 9700 South Cass Avenue, Argonne, Illinois 60439. For information about Argonne and its pioneering science and technology programs, see www.anl.gov.
\end{abstract}

\title{
DOCUMENT AVAILABILITY
}

Online Access: U.S. Department of Energy (DOE) reports produced after 1991 and a growing number of pre-1991 documents are available free via DOE's SciTech Connect (http://www.osti.gov/scitech/).

Reports not in digital format may be purchased by the public from the National Technical Information Service (NTIS):

U.S. Department of Commerce

National Technical Information Service

5301 Shawnee Road

Alexandria, VA 22312

unw.ntis.gov

Phone: (800) 553-NTIS (6847) or (703) 605-6000

Fax: (703) 605-6900

Email: orders@ntis.gov

Reports not in digital format are available to DOE and DOE contractors from:

U.S. Department of Energy

Office of Scientific and Technical Information

P.O. Box 62

Oak Ridge, TN 37831-0062

\section{Disclaimer}

This report was prepared as an account of work sponsored by an agency of the United States Government. Neither the United States Government nor any agency thereof, nor UChicago Argonne, LLC, nor any of their employees or officers, makes any warranty, express or implied, or assumes any legal liability or responsibility for the accuracy, completeness, or usefulness of any information, apparatus, product, or process disclosed, or represents that its use would not infringe privately owned rights. Reference herein to any specific commercial product, process, or service by trade name, trademark, manufacturer, or otherwise, does not necessarily constitute or imply its endorsement, recommendation, or favoring by the United States Government or any agency thereof. The views and opinions of document authors expressed herein do not necessarily state or reflect those of the United States Government or any agency thereof, Argonne National Laboratory, or UChicago Argonne, LLC. 


\section{Developing Surrogate Far-Field Nuclear Fallout and Its Rapid Decontamination from Aircraft Surfaces}

by

William C. Jolin and Michael D. Kaminski

Strategic Security Sciences Division, Argonne National Laboratory

April 2019 



\section{Table of Contents}

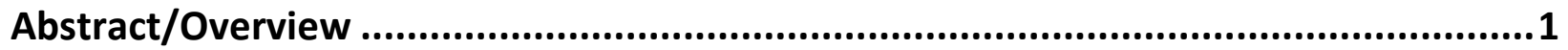

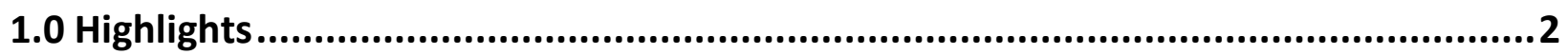

2.0 Silicate Coating to Prevent Leaching from Radiolabeled Surrogate Far-Field Fallout in Aqueous Environments.........................................................................3

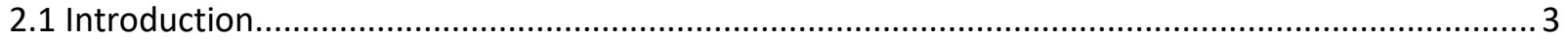

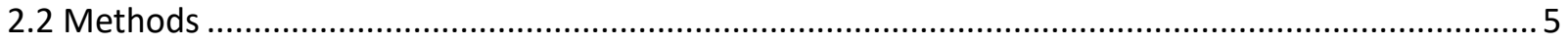

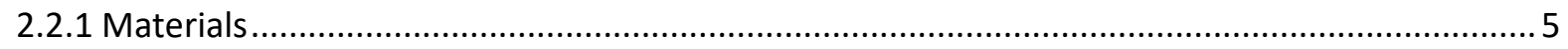

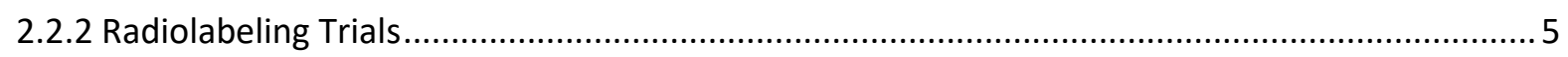

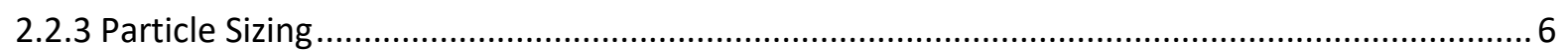

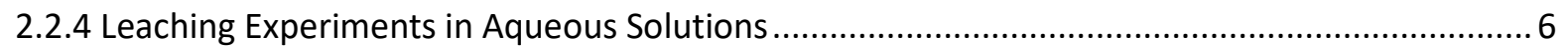

2.2.5 Leaching into Strippable Decontaminants.............................................................................. 7

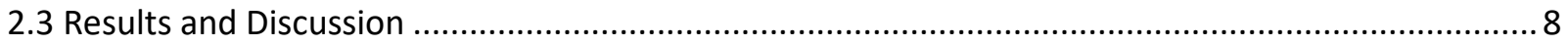

2.3.1 Leveraging $\mathrm{Eu}_{2}\left(\mathrm{SiO}_{3}\right)_{3}$ or $\mathrm{Am}_{2}\left(\mathrm{SiO}_{3}\right)_{3}$ as Precipitation Methods ............................................ 8

2.3.2 Calcination to Anhydrous Complexes................................................................................. 8

2.3.3 Melting and Thermal Decomposition at High Temperature .................................................. 10

2.3.4 Two-Step Process: Decomposition of $\mathrm{Eu}\left(\mathrm{NO}_{3}\right)_{3}$ and Silicate Layering ...................................... 11

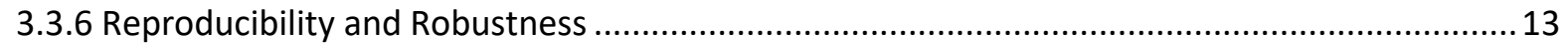

3.3.5 Further Leaching Studies into Aqueous Solution of Interest................................................. 14

2.4 Conclusions

3.0 Particle Application Method...............................................................................17

4.0 Positive Blanks and the Potential for Cross-contamination ...................................19

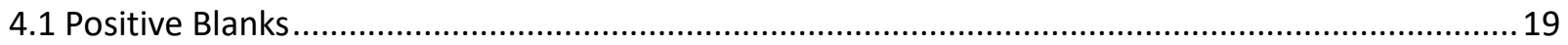

4.2 Potential for Cross-contamination and Negative Blanks .......................................................... 20

5.0 Static Test Kinetics ............................................................................................21

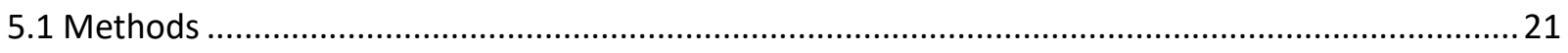

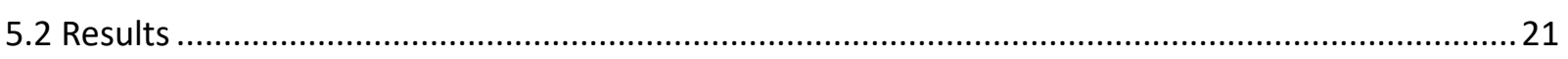

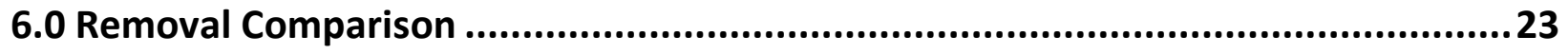

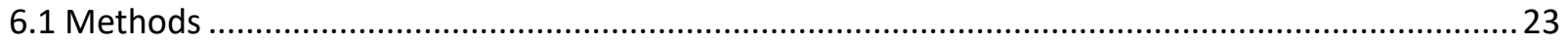

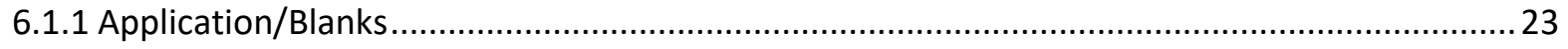

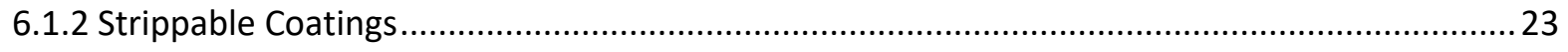

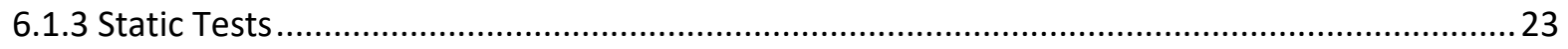




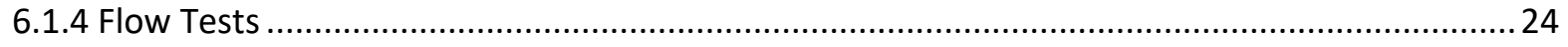

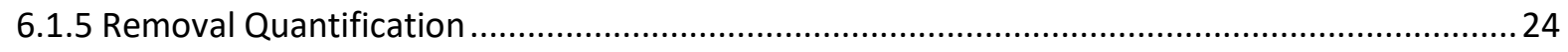

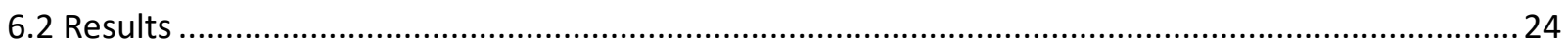

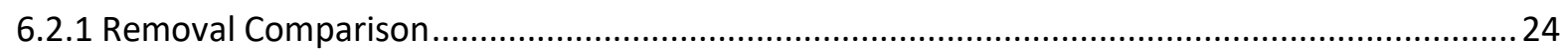

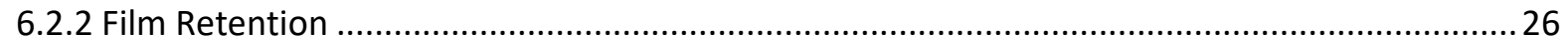

6.2.3 Multiple Decontaminations and Second Cesium Contamination Event ..................................27

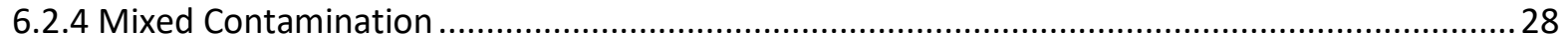

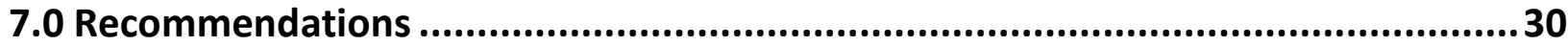

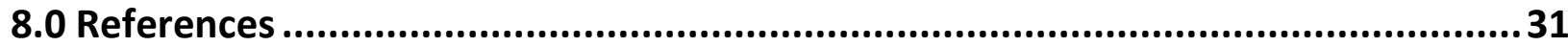

Appendix 1: Particle Synthesis Standard Operating Procedure ...............................34

Appendix 2: Supplemental Information for Particle Method ................................36

Appendix 3: Visual Log of Cesium Removals ..................................................40 


\section{Developing Surrogate Far-Field Nuclear Fallout and Its Rapid Decontamination from Aircraft Surfaces}

\section{Abstract/Overview}

Naval aircraft and vehicles deployed in response to the tsunami of 2011 and subsequent nuclear meltdown at the Fukushima Daiichi nuclear power station were exposed to and contaminated with radioactive materials released to the atmosphere. In response, the Navy and Argonne National Laboratory are testing various decontamination methods to clean aircraft surfaces exposed to far-field nuclear fallout. Far-field fallout, which can travel hundreds of miles, includes dissolved radionuclides and fine particulate matter. To simulate contamination with such materials, dissolved cesium-137 $\left({ }^{137} \mathrm{Cs}\right)$ and radiolabeled particles were deposited on coupons ( $1 \times 1$ in. sections) of tire, acrylic, and painted metal surfaces. These coupons were subjected to six different decontamination methods, including ones involving four strippable products, a soap solution, and tap water. Removals of dissolved ${ }^{137} \mathrm{Cs}$ were generally high: over $90 \%$ of the deposited radionuclide was removed after three decontaminations.

To simulate exposure to inert, radioactive fallout or other inert, airborne particulate, silica $\left(\mathrm{SiO}_{2}\right)$ particles were used as surrogate fine particulate matter. The silica particles were radiolabeled by first depositing europium-152 $\left({ }^{152} \mathrm{Eu}\right)$ or americium-241 $\left({ }^{241} \mathrm{Am}\right)$ on the particle surface as sesquioxides $\left(\mathrm{Eu}_{2} \mathrm{O}_{3}\right.$ or $\left.\mathrm{Am}_{2} \mathrm{O}_{3}\right)$, then coating it with sodium silicate. Scanning electron microscopy confirmed that particle size was not altered by the treatment, while leaching studies into numerous solutions and decontamination agents confirmed that minimal amounts of the radiolabel dissolved into solution. Three different methods to apply the radioactive particles to the silica were evaluated. Pressing the coupons into a dish containing the particles resulted in particle clumping on the surface, while applying the particles within water also resulted in heterogeneous surface coverage. Suspending the particles in ethanol and then applying them to the surface supplied homogeneous surface coverage that provided acute and precise removal percentages. Finally, particle-surface interactions seemingly play an important role in radiological decontamination as the removal percentages were lower than those of soluble ${ }^{137} \mathrm{Cs}$ for aqueous decontamination methods. These decreased removal percentages indicate that more complex methods such as strippable decontamination agents are required to remove particulate far-field fallout from aircraft and similar vehicle surfaces. 


\subsection{Highlights}

- A method was developed to radiolabel silica particles by first depositing ${ }^{152} \mathrm{Eu}$ or ${ }^{241} \mathrm{Am}$ on the particle surface as sesquioxides, then coating the particle with sodium silicate (procedure provided in Appendix 1).

- Suspending the particles in ethanol and then applying them to the surface supplied homogeneous surface coverage that provided acute and precise removal percentages.

- Six decontamination agents were tested: four strippable agents (applied to surface, dried, and peeled off) and two aqueous agents (flowed over surface).

- Four aircraft surfaces were tested: acrylic windscreen, tire rubber, high gloss painted aluminum, and low gloss painted aluminum.

- Removals of dissolved ${ }^{137} \mathrm{Cs}$ that was deposited wet on the surface were high for all strippable agents and for aircraft soap flowed over the surface.

- Removal of surrogate radioactive particles was low for aqueous agents. Strippable agents removed particle contaminations distinctly better.

- Little difference was seen between removals of a mixture of contamination types and removals of each contamination type alone.

- Strippable decontamination agents were effective in removing both soluble radioactive and radioactive particles from naval aircraft surfaces.

- Aqueous aircraft soap solution (4:1 ratio of tap water to SSDX-12 concentrate) was only effective in removing soluble cesium while tap water was not effective, especially from rough surfaces. 


\subsection{Silicate Coating to Prevent Leaching from Radiolabeled Surrogate Far-Field Fallout in Aqueous Environments}

\subsection{Introduction}

The morphology and size of radioactive particles govern the fate of radioactivity in the environment and the efficacy of various decontamination techniques. Recent insights into radioactive particle size and mineralogy indicate that a large percentage of the radioactivity observed during the Fukushima Daiichi nuclear meltdown was insoluble cesium-137 $\left({ }^{137} \mathrm{Cs}\right)$ bound within glass-like silica microparticles [1-6] rather than wet-deposited, soluble ${ }^{137} \mathrm{Cs}$ as previously thought $[7,8]$. Many of the most radioactive particles were in the range of 0.5-3 $\mu \mathrm{m}$ $[1,4,9]$. The most radioactive particles deposited on surfaces were 2-2.6 $\mu \mathrm{m}$ in diameter $[1,4]$, while the most radioactive airborne particles had aerodynamic diameters < $0.95 \mu \mathrm{m}$ [9]. Similarly sized particles were also found after the Chernobyl meltdown in 1985 [9-11] and after atmospheric weapons testing [12]. Particles of this size are a concern since they are in the respirable range [13] and have drastically different physical and chemical properties compared to soluble radionuclides. Of note, the smaller particle size allows radioactivity to be transported long distances and to deposit as far field fallout [14-16]. Further, these particles are orders of magnitude smaller than the hundreds of micrometers in diameter originally used in decontamination research [17, 18]. Proper decontamination testing of surfaces and environmental fate studies require surrogate particles of the correct size to effectively simulate conditions after a future nuclear event. These surrogate materials must also be insoluble in aqueous environments to mimic the properties of the released particles. Though some work has used radiolabeled silica particles for decontaminant testing [19], most studies simply sorb the radiolabel to the surface of the silica, thereby making it susceptible to leaching into aqueous decontamination agents and aquatic environments. Therefore, a need exists for a method that irreversibly binds a labeling radionuclide to micrometer-sized silica particles.

The insoluble cesium/silica microparticles found after the Fukushima incident are formed by the rapid cooling of aerosols at extreme temperature [1, 2]. Replicating such a process is not feasible at the laboratory scale without highly specialized equipment and working conditions, especially to produce the quantity of particles needed for proper decontamination or environmental transport studies. Therefore, a method is needed to irreversibly bind radionuclides within or onto surrogate micrometer-sized silica particles. Introducing the radiolabel during the formation process would result in a radiolabel embedded within the crystal structure, reducing the possible leaching of the radiolabel. Such a process has been deployed in creating 0.3-0.7 $\mu \mathrm{m}$ silica microparticles for biomedical applications, where ${ }^{75}$ Se nanoparticles were encapsulated in silica microparticles by multiple polymerization coatings of tetraethoxysilane through the Stöber process [20]. However, this production method would need to be drastically altered to produce particles within the 2.0-2.6 $\mu \mathrm{m}$ range, as diminishing returns in particle growth were displayed with each coating. Therefore, establishing an irreversible 
radiolabeling method that does not require alteration of already established production techniques would save researchers time in method development and analysis.

In biomedical applications, silica particles are commonly tagged with a variety of radionuclides and made inert through ion-organic ligand complexes attached to functionalized surfaces. This technique is designed to create particles of the correct size but is not concerned with, or purposely changes, the surface of the particles [21, 22]. However, surface chemistry is vitally important in particle-surface interactions, and a silicon oxide outer layer would be more representative of nuclear fallout. Clark et al. radiolabeled large sand particles by encapsulating ${ }^{140}$ La within a silica layer by mixing sodium silicate, ${ }^{140} \mathrm{La}$, and sand in a cement mixer and baking the mixture at $1100^{\circ} \mathrm{C}\left(2000^{\circ} \mathrm{F}\right)[23,24]$. Less than $1 \%$ of the radiolabel from these particles leached into tap water [25]. No size analysis was performed on these particles, raising concerns that particle size may be increased by either creating too thick a silica layer or through particle clumping. To minimize the particle growth and aggregation, a volatile diluent could be used to spread the sodium silicate coating before heat treatment. For instance, ethanol has been used to disperse particles and spread an organic coating on magnetic microparticles [26]. Ethanol could also be leveraged to precipitate a silica layer on the surface of the particle by converting $\mathrm{Na}_{2} \mathrm{SiO}_{3}$ to $\mathrm{SiO}_{2}$ through hydrolysis and condensation of silicate ions in aqueous micelles within ethanol [27]. However, the coating would need to be thin enough such that the overall size of the particle is not changed. Further, the optimal coating procedure, including mixing volume and heat treatment temperature, must be determined, especially given the wide range of temperatures used for sodium silicate activation $\left(80^{\circ} \mathrm{C}\right.$ to $\left.1100^{\circ} \mathrm{C}\right)$ depending on the desired end product [24, 28-30].

In response to the above needs, we developed and tested a method for securing ${ }^{152} \mathrm{Eu}$ or ${ }^{241} \mathrm{Am}$ on 0.5 and $2 \mu \mathrm{m}$ silica particles within a silica coating. We concluded that a step-wise method that first deposited ${ }^{152} \mathrm{Eu}$ or ${ }^{241} \mathrm{Am}$ as sesquioxides and encapsulated the oxides in a silica coating through the heating of sodium silicate led to the desired coating thickness while minimizing leaching into solution. Trivalent radionuclides were chosen to mimic the labeling of sand with ${ }^{140} \mathrm{La}$ and to provide a number of radionuclides with varied half-life that could be substituted (i.e., ${ }^{140} \mathrm{La},{ }^{151} \mathrm{Gd},{ }^{125} \mathrm{Sb}$ ) depending on the desired use. Light scattering and scanning election microscopy confirmed that particle size was not changed from that of the original particles. Leaching studies into tap water, surfactant solution, and $0.5 \mathrm{M}$ nitric acid, as well as two strippable decontamination agents, were performed to ensure particle inertness. In this report, we discuss numerous systematic trials in developing the procedure and highlight the insights gained into the interactions of europium and americium with silicon oxides. 


\subsection{Methods}

\subsubsection{Materials}

Silica microspheres 0.5 and $2 \mu \mathrm{m}$ in diameter were purchased from Sigma Aldrich and used without further purification. ${ }^{152} \mathrm{Eu}$ and ${ }^{241} \mathrm{Am}$ dissolved in $5 \mathrm{M}$ nitric acid were purchased from Eckert and Ziegler. Radiolabeling solutions were created by diluting each stock to contain 0.3 to $0.5 \mu \mathrm{Ci} \mu \mathrm{L}^{-1}$. Since the $0.5 \mu \mathrm{m}$ and $2 \mu \mathrm{m}$ particles were to be used together in experiments, they were radiolabeled with ${ }^{241} \mathrm{Am}$ and ${ }^{152} \mathrm{Eu}$, respectively. Deionized water $(18.2 \mathrm{M} \Omega \cdot \mathrm{cm})$ was obtained from a Thermo-Fisher nanopure system. Ethanol (99.5\% pure) was purchased from Sigma Aldrich. Three decontamination agents, a temporary removable coating, a gel product, and a special aircraft soap were obtained through suppliers and used as received. Tap water was supplied by the DuPage County Department of Public Works, which routinely analyzes it. We previously analyzed a sample of the tap water by inductively coupled plasma mass spectrometry and found good agreement with reported values for metal content [31]. We also prepared artificial seawater and rainwater. The artificial seawater contained 53.1, 444.4, 10.2, and $10.2 \mathrm{mM}$ of $\mathrm{MgCl}_{2}, \mathrm{NaCl}, \mathrm{CaCl}_{2}$, and $\mathrm{KCl}$, respectively, in deionized water raised to $\mathrm{pH} 8.2$ with $\mathrm{KOH}$. The artificial rain water was deionized water left overnight on a bench top until pH 5.5 was reached, which was subsequently lowered to $\mathrm{pH} 4.5$ with $\mathrm{H}_{2} \mathrm{SO}_{4}$. All other chemicals and reagents were ACS grade.

\subsubsection{Radiolabeling Trials}

We followed a general method in creating a silica layer to encapsulate the radiolabeling nuclides. First, $50 \mathrm{mg}$ of dry silica particles of the selected size was placed in a $2 \mathrm{~mL}$ centrifuge tube, which was spiked with $90 \mu \mathrm{L}$ of ethanol and $2.5 \mu \mathrm{L}$ of the respective radiolabeling solution, followed by $10 \mu \mathrm{L}$ of $1 \mathrm{M} \mathrm{Na}_{2} \mathrm{SiO}_{3}$ solution. This $\mathrm{Na}_{2} \mathrm{SiO}_{3}$ spike is predicted to leave a 18 and $4.5 \mathrm{SiO}_{2}$ molecule thick layer on the surface for 2 and $0.5 \mu \mathrm{m}$ particles, respectively, each giving rise to less than a $1 \%$ change in the particle diameter (see Appendix 2 and Table A2.1). The ratio of 9:1 ethanol to $1 \mathrm{M} \mathrm{Na}_{2} \mathrm{SiO}_{3}$ solution was used because a higher volume of $\mathrm{Na}_{2} \mathrm{SiO}_{3}$ led to a noticeably viscous residue after drying. The sample was centrifuged for $3 \mathrm{~min}$ at $2000 \mathrm{~g}$ to ensure contact between all particles and the solution, mixed on a Fisher Vortex Mixer for 5 min (setting 2), sonicated in distilled water for $15 \mathrm{~min}$, and air dried for $30 \mathrm{~min}$. The sample was vertically oriented throughout the drying process to minimize particle adhesion to the walls of the container. This drying procedure was repeated until the sample was dry (generally three times).

Once dry, several treatment temperatures were evaluated, including further drying at room temperature $\left(20-25^{\circ} \mathrm{C}\right)$ overnight, drying at $90^{\circ} \mathrm{C}$ overnight, and baking for 1 hour at $500^{\circ} \mathrm{C}$, $750^{\circ} \mathrm{C}$, or $1125^{\circ} \mathrm{C}$ within a muffle furnace (Fisher Scientific). Each temperature was independently verified with a type $\mathrm{K}$ thermocouple. For $750^{\circ} \mathrm{C}$ and $1125^{\circ} \mathrm{C}$, the sample was transferred to either an alumina or zirconia crucible and brought to temperature at $10^{\circ} \mathrm{C} \mathrm{min}^{-1}$ to avoid thermal shock. For $500^{\circ} \mathrm{C}$, the sample was transferred to an aluminum dish and placed in the furnace directly at 
temperature, while for $90^{\circ} \mathrm{C}$ and air drying the sample was kept in the original centrifuge tube. After heat treatment, the sample was transferred to a new centrifuge tube (except for the $90^{\circ} \mathrm{C}$ and room temperature tests) and spiked with $1 \mathrm{~mL}$ of deionized water. The sample was sonicated for 10 min, vigorously shaken, and counted on an Ortec Detective high purity germanium isotope identifier for $5 \mathrm{~min}$. The sample was then centrifuged at $2000 \mathrm{~g}$ for $3 \mathrm{~min}$, after which a $100 \mu \mathrm{L}$ aliquot was taken. A second $650 \mu \mathrm{L}$ aliquot was obtained and discarded before the sample was spiked with $750 \mu \mathrm{L}$ of new deionized water. This wash procedure was repeated a total of three times. The $100 \mu \mathrm{L}$ aliquots were placed in a gamma tube, diluted to $1 \mathrm{~mL}$ in deionized water, and counted for 10 min on a Wizard ${ }^{2}$ sodium iodide automatic gamma counter (Perkin Elmer).

Multiple alterations to the coating procedure were attempted to create particles of the correct size with minimal leaching. For these methods, only the differences from the original methods are discussed while the rest of the procedure was the same as described above. In one case, deionized water was substituted for ethanol and baked at $500^{\circ} \mathrm{C}$ to ensure that ethanol was not interfering with the formation of $\mathrm{Eu}_{2}\left(\mathrm{SiO}_{3}\right)_{3}$ or causing the premature precipitation of $\mathrm{SiO}_{2}$. Similarly, two samples were prepared without ethanol, where either $100 \mu \mathrm{l}$ of $1 \mathrm{M} \mathrm{Na}_{2} \mathrm{SiO}_{3}$ solution or $1 \mathrm{M} \mathrm{Na}_{2} \mathrm{CO}_{3}$ solution was used. These samples were baked at $550^{\circ} \mathrm{C}$. At $1125^{\circ} \mathrm{C}$ and $750^{\circ} \mathrm{C}$, trials were performed where $1 \mathrm{M} \mathrm{Na}_{2} \mathrm{CO}_{3}$ was substituted for $1 \mathrm{M} \mathrm{Na}_{2} \mathrm{SiO}_{3}$. Also at $1125^{\circ} \mathrm{C}$ and $750^{\circ} \mathrm{C}$, trials were performed when only $100 \mu \mathrm{L}$ of ethanol and $2.5 \mu \mathrm{L}$ of either radiolabeling solution were spiked into the samples. The final trial spiked the particles with $100 \mu \mathrm{L}$ of ethanol and $2.5 \mu \mathrm{L}$ of either radiolabeling solution. The sample was dried and baked at $750^{\circ} \mathrm{C}$. Then, the sample was washed three times with deionized water, dried overnight, and coated with $90 \mu \mathrm{L}$ of ethanol plus $10 \mu \mathrm{L}$ of $1 \mathrm{M} \mathrm{Na}_{2} \mathrm{SiO}_{3}$, dried, and baked at $750^{\circ} \mathrm{C}$ (in essence going through the procedure twice: one with the radiolabel and the second with the coating) before being washed and dried.

\subsubsection{Particle Sizing}

Particle size and shape were determined at high magnification using a Hitachi S-3000N scanning electron microscope (SEM). Energy dispersive X-ray spectroscopy (EDS) was also performed using NSS microanalysis software (ThermoFisher). Bulk particle sizing through dynamic light scattering was performed with the particle analysis software package of a Brookhaven Zeta Potential Analyzer (Brookhaven instruments), where the silica particles were suspended in deionized water and assumed to be spheres with a refractive index of 1.47 [32]. Each sample was counted 10 times for one minute at a $661 \mathrm{~nm}$ wavelength.

\subsubsection{Leaching Experiments in Aqueous Solutions}

To ensure particle inertness, approximately $2 \mathrm{mg}$ of particles in $50 \mu \mathrm{L}$ deionized water was spiked into a centrifuge tube. Particles were allowed to dry and then spiked with $1 \mathrm{~mL}$ of solution. For preliminary screening of leachability, tap water and a 4:1 ratio of tap water to aircraft soap concentrate (soap solution) were used. Final leaching characterization of particles was performed with deionized water, $0.5 \mathrm{M}$ nitric acid, and artificial seawater and rainwater. The samples were 
mixed until suspended, then counted on an Ortec Detective for $5 \mathrm{~min}$. The sample was then placed on a rotating mixer for 1 hour (tap water, soap solution, and $0.5 \mathrm{M}$ nitric acid), 72 hours (artificial sea and rainwater), and 30 days (deionized water), after which 100 and $250 \mu \mathrm{L}$ aliquots were removed from the sample. The $100 \mu \mathrm{L}$ aliquot was placed in a gamma tube, diluted to $1 \mathrm{~mL}$ in deionized water, and counted for $10 \mathrm{~min}$ on the Wizard ${ }^{2}$. The $250 \mu \mathrm{L}$ aliquot was placed in an ultra-centrifuge tube $(0.22 \mu \mathrm{m}$ filter $)$ and centrifuged at $2000 \mathrm{~g}$ for $5 \mathrm{~min}$. Duplicate $100 \mu \mathrm{L}$ aliquots were taken of the filtrate, which were diluted to $1 \mathrm{~mL}$ in a gamma tube before counting for 10 min on the Wizard ${ }^{2}$. Generally, no difference was seen between the filtered and unfiltered samples. This indicates that most particles were removed from solution during centrifugation, which was confirmed by Stokes law. Percent leached was determined from counts within the aliquots and those of the initial samples after accounting for the difference in counts from the Ortec Detective and the Wizard ${ }^{2}$ due to tube orientation and shape, crystal size, and window thickness. A sample holder was used on the Ortec Detective to keep the samples angled at $45^{\circ}$, with the center of mass approximately $1 \mathrm{~cm}$ from the surface of the detector and the centrifuge tube tip touching the detector. The Wizard ${ }^{2}$ was found to provide 34.8 times more counts than the Ortec Detective for ${ }^{152} \mathrm{Eu}(344 \mathrm{keV}$ ), and 73.8 times more for the lower energy gamma of ${ }^{241} \mathrm{Am}(60 \mathrm{keV})$.

\subsubsection{Leaching into Strippable Decontaminants}

We also wanted to ensure that our particles were not leaching into the established strippable coatings during the decontamination tests. These coatings are designed to be applied wet, allowed to dry, and stripped off the surface. Leaching was performed with a gel-based product and a temporary removable coating. To establish whether the radiolabel leaches from the particles in this process, 4-5 mg of radiolabeled particles was spiked onto a Petri dish with $100 \mu \mathrm{L}$ of deionized water. The particles were dried overnight. Once dry, 2-3 g of either strippable coating was spread within the Petri dish and allowed to dry. The film was then peeled from the dish, placed in a $2 \mathrm{ml}$ centrifuge tube, condensed with a spatula to approximately $1 \mathrm{~mL}$ volume, and counted on an Ortec Detective for $5 \mathrm{~min}$. The film was then transferred to a $15 \mathrm{~mL}$ centrifuge tube and spiked with $10 \mathrm{~mL}$ or either deionized water (gel product) or acetone (removable coating) to dissolve the strippable agents. The films were dissolved for $18 \mathrm{~h}$, then centrifuged at $2000 \mathrm{~g}$ for $10 \mathrm{~min}$. Quintuplet $1 \mathrm{~mL}$ aliquots were taken of the supernatant and counted on the Wizard $^{2}$. Samples were also prepared where only diluted radiolabel solutions were spiked into the Petri dish to establish the amount of each radionuclide that can be recovered from each strippable agent. We were concerned that ${ }^{152} \mathrm{Eu}$ and ${ }^{241} \mathrm{Am}$ were sparingly soluble in acetone. Therefore, after the initial aliquot was taken, the sample was spiked with deionized water, mixed for $45 \mathrm{~min}$, and resampled. No difference was seen between these samples and the original aliquots after accounting for the two-fold dilution. Finally, counts within the aliquot from the $0.5 \mu \mathrm{m}$ particles in the gel product were much higher than other samples. We attributed this finding to incomplete settling of the particles due to the higher viscosity of the dissolved gel 
product. Therefore, $100 \mu \mathrm{L}$ of each aliquot, including that for dissolved radionuclide only, was passed through a $0.22 \mu \mathrm{m}$ ultra-centrifuge tube, diluted to $1 \mathrm{~mL}$, and counted on the Wizard².

\subsection{Results and Discussion}

\subsubsection{Leveraging $\mathrm{Eu}_{2}\left(\mathrm{SiO}_{3}\right)_{3}$ or $\mathrm{Am}_{2}\left(\mathrm{SiO}_{3}\right)_{3}$ as Precipitation Methods}

Low temperature trials (either room temperature or $90^{\circ} \mathrm{C}$ ) were performed for a $2 \mu \mathrm{m}$

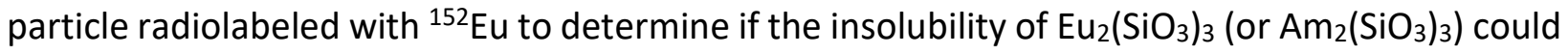
be leveraged to attach the trivalent radionuclides onto the particle surface. We expected that either radionuclide would complex with $\mathrm{SiO}_{3}{ }^{2-}$ within the aqueous emulsions, and would then precipitate on the particle surface. Without any heat activation, the retention on the particles would only be the result of the insolubility of $\mathrm{Eu}_{2}\left(\mathrm{SiO}_{3}\right)_{3}$, which is likely in the form of a hydrated complex $\left(\mathrm{Eu}_{2}\left(\mathrm{SiO}_{3}\right)_{3} \cdot \mathrm{nH}_{2} \mathrm{O}\right)$. These complexes were expected to have minimum solubility in NANOpure ${ }^{\mathrm{TM}}$ water [33]. However, approximately $50 \%$ of the initial ${ }^{152} \mathrm{Eu}$ was removed within the washes. Hydrated complexes of $\mathrm{Eu}_{2}\left(\mathrm{SiO}_{3}\right)_{3}$ are seemingly quite soluble and an inadequate retention mechanism for ${ }^{152} \mathrm{Eu}$ on silica. Leaching or size analysis was not performed because of the large amount of the radiolabel lost in the deionized water.

Baking at $90^{\circ} \mathrm{C}$ removes more water (than air drying) and should lower the number of water molecules (n) within $\mathrm{Eu}_{2}\left(\mathrm{SiO}_{3}\right)_{3} \cdot \mathrm{nH}_{2} \mathrm{O}$. In addition, the increase in temperature should ensure that all residual $\mathrm{HNO}_{3}$ from the radiolabeling stocks is evaporated. Distinctly fewer radioactive counts were seen in the washes after baking at $90^{\circ} \mathrm{C}$ compared to air drying. Even more promising, only $1.2 \%$ of radionuclide leached into tap water. However, a large amount of leaching in soap solution was observed as $26 \%$ of the initial counts were removed from the particles. The surfactants within the soap solution are seemingly able to either dissolve more of the silicate layer and release ${ }^{152} \mathrm{Eu}$ or can access more of the micropores and remove the ${ }^{152} \mathrm{Eu}$ bound within.

\subsubsection{Calcination to Anhydrous Complexes}

We increased the temperature of heat treatment to $500^{\circ} \mathrm{C}$ to ensure that all water was removed from the silicate- ${ }^{152} \mathrm{Eu} /{ }^{241} \mathrm{Am}$ complexes. Calcination at $500^{\circ} \mathrm{C}$ dehydrates silica layers formed from sodium silicate without altering the crystal structure [28]. Such a heat treatment is also expected to dehydrate $\mathrm{Eu}_{2}\left(\mathrm{SiO}_{3}\right)_{3} \cdot \mathrm{nH}_{2} \mathrm{O}$ [28], leading to insoluble $\mathrm{Eu}_{2}\left(\mathrm{SiO}_{3}\right)_{3}$ or $\mathrm{Am}_{2}\left(\mathrm{SiO}_{3}\right)_{3}$. These insoluble complexes bound within the silica outer layer should be inaccessible to the surrounding solution. Accordingly, little leaching into tap water was observed for either sized particles, as $0.02 \%$ leached for $2 \mu \mathrm{m}$ labeled with ${ }^{152} \mathrm{Eu}$ and $0.08 \%$ for $0.5 \mu \mathrm{m}$ labeled with ${ }^{241} \mathrm{Am}$. However, leaching was still observed in soap solution as $20 \%$ of the ${ }^{152} \mathrm{Eu}$ and $6 \%$ of the initial counts of ${ }^{241} \mathrm{Am}$ were removed from the particles by the soap solution. With this, we became concerned that silica may be precipitating as separate nanoparticles, exposing the radiolabel. 
SEM analysis and a water-only trial ensured that ethanol was not causing the precipitation of separate silica nanoparticles. High-resolution SEM images of particles coated with sodium silicate in ethanol without a radiolabel did show smaller silica particles, which may be indicative of precipitation of silica nanoparticles (Fig. A1). However, these nanoparticles were also seen in SEM analysis of unmodified particles (Fig. A2) and are likely byproducts of the original microparticle production process. Next, we ensured ethanol was not interfering with the formation of $\mathrm{Eu}_{2}\left(\mathrm{SiO}_{3}\right)_{3}$ or causing the precipitation of $\mathrm{SiO}_{2}$ without the radiolabel by substituting deionized water. Leaching was still present as $15 \%$ of the ${ }^{152} \mathrm{Eu}$ was removed from $2 \mu \mathrm{m}$ coated particles in soap solution, leading us to conclude that ethanol was not the cause of the observed leaching.

Increasing the amount of sodium silicate or using sodium carbonate to create $\mathrm{Eu}_{2} \mathrm{O}_{3} \cdot \mathrm{CO}_{2}$ on the surface decreased leaching, but either left liquid glass residue or caused the particles to clump together. We were concerned that there was an insufficient amount of sodium silicate to encapsulate the radiolabel onto the particles, and $100 \mu \mathrm{l}$ of $1 \mathrm{M} \mathrm{Na}_{2} \mathrm{SiO}_{3}$ aliquot was substituted for the $90 \mu \mathrm{l}$ ethanol $+10 \mu \mathrm{l}$ of $1 \mathrm{M} \mathrm{Na}_{2} \mathrm{SiO}_{3}$ aliquot. Another sample was similarly prepared, but $\mathrm{Na}_{2} \mathrm{CO}_{3}$ was substituted for $\mathrm{Na}_{2} \mathrm{SiO}_{3}$ in an attempt to precipitate $\mathrm{Eu}_{2}\left(\mathrm{CO}_{3}\right)_{3}$ on the particle surface. Both samples were baked at $550^{\circ} \mathrm{C}$, which should remove any residual water and decompose $\mathrm{Eu}_{2}\left(\mathrm{CO}_{3}\right)_{3}$ into insoluble $\mathrm{Eu}_{2} \mathrm{O}_{3} \cdot \mathrm{CO}_{2}$ [33-35]. Leaching for both of these tests was quite low as $0.13 \%$ and $0.27 \%$ of ${ }^{152} \mathrm{Eu}$ was removed from the particles within the soap solution for $\mathrm{Na}_{2} \mathrm{SiO}_{3}$ and $\mathrm{Na}_{2} \mathrm{CO}_{3}$, respectively. However, SEM images revealed that the excess salt left a residue of liquid glass $\left(\mathrm{Na}_{2} \mathrm{SiO}_{3}\right.$, Fig. 1.A) or caused the particles to clump together $\left(\mathrm{Na}_{2} \mathrm{CO}_{3}\right.$, Fig. 1.B). EDS revealed that the glassy residue was composed mostly of silicon and oxygen while sodium and other trace salts were present $(\mathrm{Mg}, \mathrm{Ca}$, and $\mathrm{Cl}$ ). Sodium chloride crystals were also observed and likely introduced as impurities that were incompletely removed by the washes due to the higher quantities of salt applied. As such, we concluded that using larger amounts of either $\mathrm{Na}_{2} \mathrm{SiO}_{3}$ or $\mathrm{Na}_{2} \mathrm{CO}_{3}$ results in excess salts coagulating the particles or leaving behind a residue. 

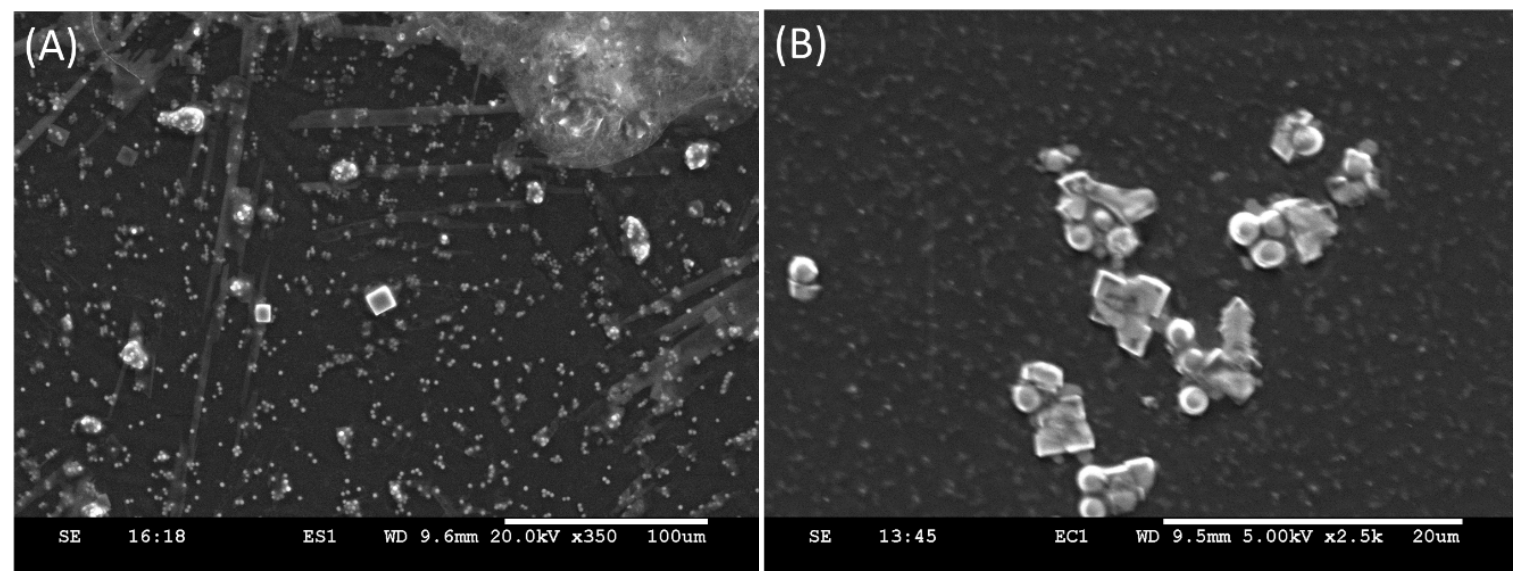

Figure 1. (A) Low magnification SEM image of $2 \mu \mathrm{m}$ particles coated in $100 \mu \mathrm{L}$ of $1 \mathrm{M} \mathrm{Na}_{2} \mathrm{SiO}_{3}$ and baked at $550^{\circ} \mathrm{C}$. Image shows particle clumping and a liquid glass residue (top right corner). (B) High magnification SEM image of $2 \mu \mathrm{m}$ particles coated in $100 \mu \mathrm{L}$ of $1 \mathrm{M} \mathrm{Na}_{2} \mathrm{CO}_{3}$ and baked at $550^{\circ} \mathrm{C}$. Image shows particles clumped together due to excess salts.

\subsubsection{Melting and Thermal Decomposition at High Temperature}

Particles were fused together if temperatures used in the original work by Clark et al. were reached. Clark et al. baked sand, ${ }^{140} \mathrm{La}$, and $\mathrm{Na}_{2} \mathrm{SiO}_{3}$ solution at $1100^{\circ} \mathrm{C}$, which is near the melting point of $\mathrm{Na}_{2} \mathrm{SiO}_{3}\left(1088^{\circ} \mathrm{C}\right)$. We attempted to mimic this method by baking silica, ${ }^{152} \mathrm{Eu}$, and $\mathrm{Na}_{2} \mathrm{SiO}_{3}$ at $1125^{\circ} \mathrm{C}$ after using ethanol as a volatile dispersant. Samples with $\mathrm{Na}_{2} \mathrm{CO}_{3}$ solution or only the radiolabeling solution were also prepared, since $1125^{\circ} \mathrm{C}$ is well above the decomposition temperature of $\mathrm{Eu}_{2}\left(\mathrm{CO}_{3}\right)_{3}\left(850^{\circ} \mathrm{C}\right)$ [35] and the $\mathrm{Eu}\left(\mathrm{NO}_{3}\right)_{3}$ complexes $\left(750^{\circ} \mathrm{C}\right)$ formed from the evaporation of a solution containing $\mathrm{HNO}_{3}$ and $\mathrm{Eu}^{3+}$ [34]. The decomposition of both europium complexes yields insoluble $\mathrm{Eu}_{2} \mathrm{O}_{3}$. Leaching from these particles was generally low, but varied. Particles coated with $\mathrm{Na}_{2} \mathrm{SiO}_{3}$ had minimal leaching $(0.06 \%)$ into soap solution while $2 \%$ and $6 \%$ of ${ }^{152} \mathrm{Eu}$ leached from samples where $\mathrm{Eu}\left(\mathrm{NO}_{3}\right)_{3}$ and $\mathrm{Eu}_{2}\left(\mathrm{CO}_{3}\right)_{3}$ were decomposed to form $\mathrm{Eu}_{2} \mathrm{O}_{3}$, respectively. Unfortunately, SEM imaging of the $\mathrm{Na}_{2} \mathrm{SiO}_{3}$ spiked sample revealed that the particles were fused together. Grinding with mortar and pestle led to deformed particles and shards (Fig. 2.A). The same particle fusion was seen for the $\mathrm{Eu}\left(\mathrm{NO}_{3}\right)_{3}$-only sample (Fig. 2.B), indicating that the temperature is the root cause of the fusion, not the presence of sodium silicate. This fusion and uneven sheering of particles baked at $1125^{\circ} \mathrm{C}$ also confirmed our concerns that the original method by Clark et al. for radiolabeling sand led to changes in particle size. 


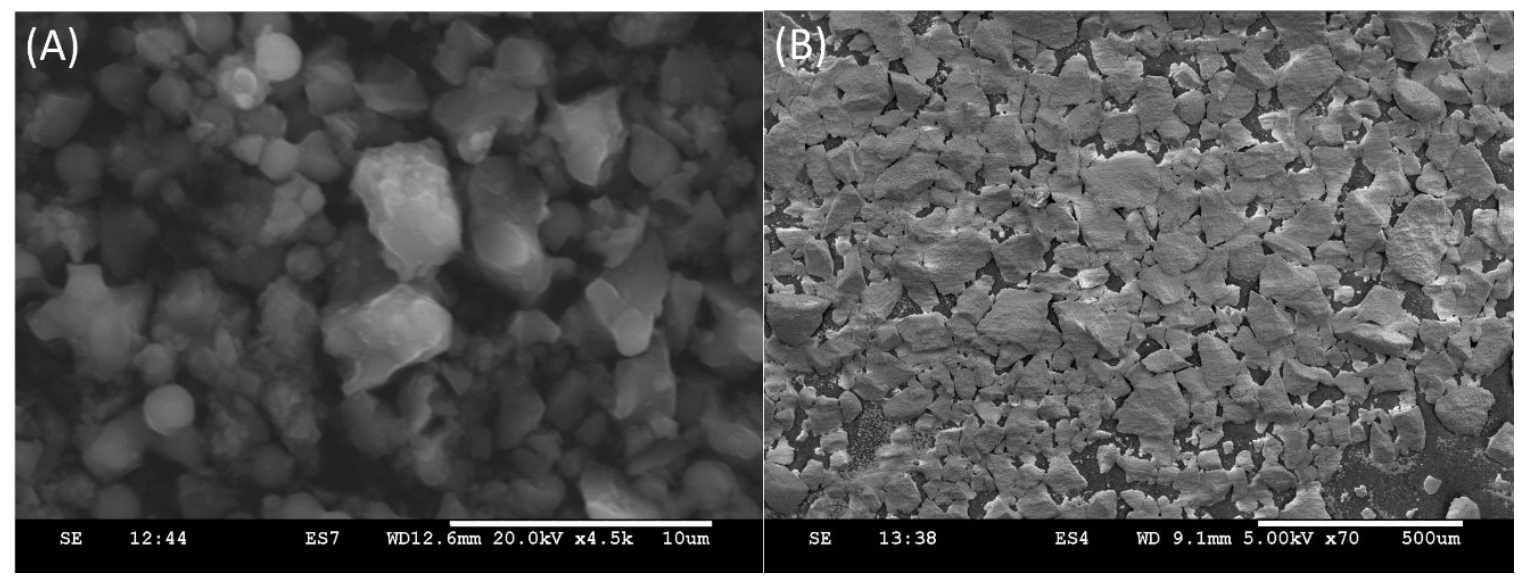

Figure 2. (A) High-magnification SEM image of $2 \mu \mathrm{m}$ particles coated in $10 \mu \mathrm{L}$ of $1 \mathrm{M} \mathrm{Na}_{2} \mathrm{SiO}_{3}$ and baked at $1125^{\circ} \mathrm{C}$. Image shows particle fusion leading to small shards of particles after grinding. (B) Lowmagnification SEM image of $2 \mu \mathrm{m}$ particles spiked with ${ }^{152} \mathrm{Eu}$ in $\mathrm{HNO}_{3}$ and baked at $1125^{\circ} \mathrm{C}$. Image shows particle fusion leading to large clumps of particles.

\subsubsection{Two-Step Process: Decomposition of Eu(NO 3$)_{3}$ and Silicate Layering}

The calcination temperature was decreased to $750^{\circ} \mathrm{C}$ to avoid the fusing of particles at $1125^{\circ} \mathrm{C}$. We started by only spiking the particle with ethanol and the radiolabeling solution in hopes that the minimal leaching seen at $1125^{\circ} \mathrm{C}$ was due to the insolubility of $\mathrm{Eu}_{2} \mathrm{O}_{3}$ and not the fusion of the particles. While the decomposition temperature of $\mathrm{Eu}\left(\mathrm{NO}_{3}\right)_{3}$, the likely precipitant, is also $750^{\circ} \mathrm{C}$ [34], SEM imaging displayed particles of the correct size (Fig. A3). However, leaching was high into soap solution (26\%) and tap water (5\%). We concluded that decomposing $\mathrm{Eu}\left(\mathrm{NO}_{3}\right)_{3}$ alone would not lead to inert particles, and the lack of leaching observed for similarly prepared particles baked at $1125^{\circ} \mathrm{C}$ was due to ${ }^{152} \mathrm{Eu}$ being bound between fused particles. Since no fusion of particles was seen at $750^{\circ} \mathrm{C}$, we again attempted to introduce $\mathrm{Na}_{2} \mathrm{SiO}_{3}$ with the radiolabel to reduce leaching.

Depositing the radiolabel as a nitrate salt, decomposing the salt to a sesquioxide, and coating it with sodium silicate provided particles of the correct size that did not leach into solution. This two-step process, which coated particles that already had $\mathrm{Eu}\left(\mathrm{NO}_{3}\right)_{3}$ decomposed to $\mathrm{Eu}_{2} \mathrm{O}_{3}$ with $\mathrm{Na}_{2} \mathrm{SiO}_{3}$, only leached $0.27 \%$ and $0.65 \%$ of ${ }^{152} \mathrm{Eu}$ into tap water and soap solution, respectively. SEM imaging revealed particles of the correct size (Fig. 3.A) with no visible clumping (Fig. 3.B). No sodium peak was detected with EDS analysis, indicating that the heat treatment and/or the silicate micelles formed within ethanol facilitate the precipitation of a strictly silica coating, while the $\mathrm{Na}_{2} \mathrm{O}$ produced as a byproduct was likely washed away. Europium was also not detected, which was expected from the small mass added. Finally, to confirm the bulk size of the particles, dynamic light scattering was performed on approximately $0.1 \mathrm{mg}$ of the particles within $2 \mathrm{~mL}$ of deionized water. The mean size of the particles was $1.91 \pm 0.03 \mu \mathrm{m}$, which was not significantly different (t-test, $\mathrm{p}<0.05$ ) than that of the unmodified particles (Table 1 ). 

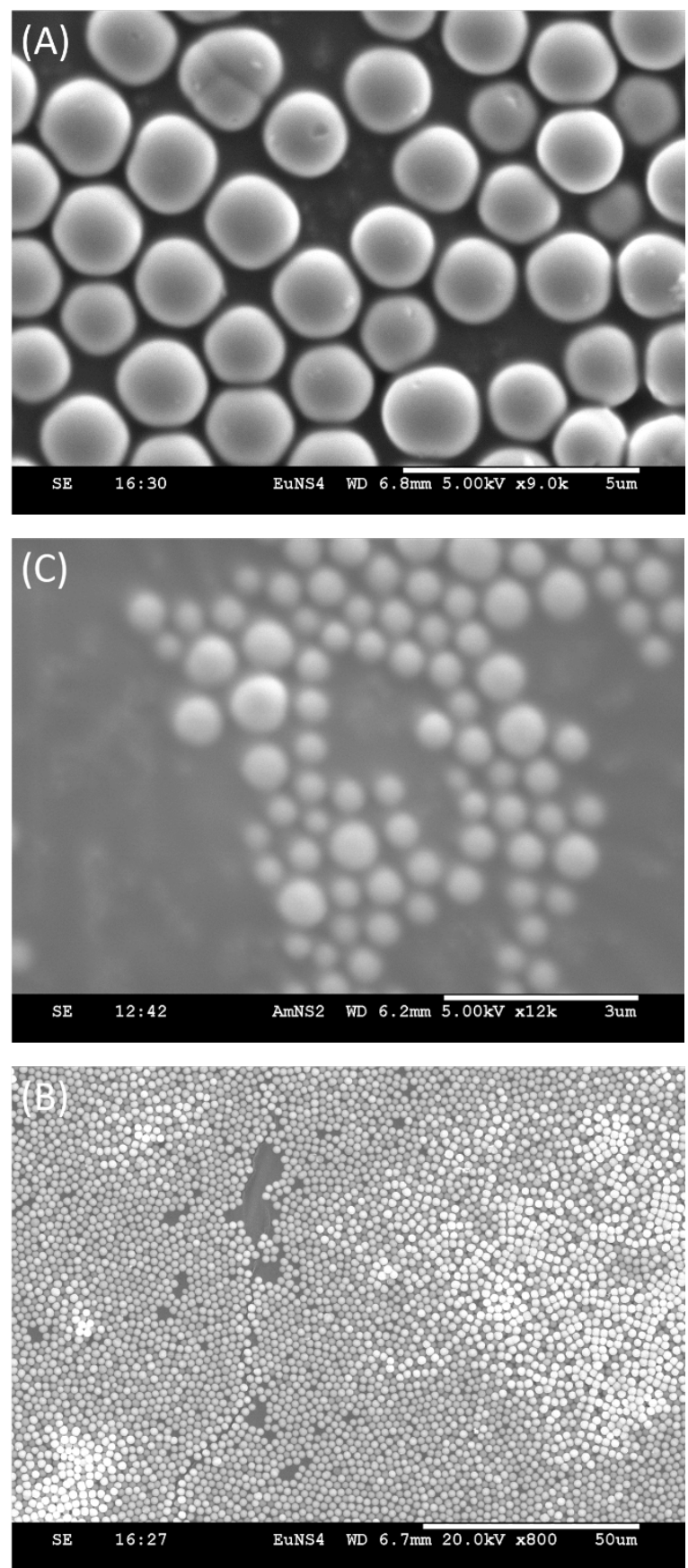

Figure 3. (A) High-magnification SEM image of $2 \mu \mathrm{m}$ particles spiked with ${ }^{152} \mathrm{Eu}$, baked at $750^{\circ} \mathrm{C}$, and then coated in $10 \mu \mathrm{L}$ of $1 \mathrm{M} \mathrm{Na}_{2} \mathrm{SiO}_{3}$. Image shows particles with no fusion. (B) Low-magnification SEM image of the same $2 \mu \mathrm{m}$ particles. Image displays no particle coagulation. (C) SEM image of the $0.5 \mu \mathrm{m}$ particles produced in the same way, but labeled with ${ }^{241} \mathrm{Am}$. 
Table 1. Dynamic light scattering results for $0.5 \mu \mathrm{m}$ and $2 \mu \mathrm{m}$ particles. Data show that size is not changed between radiolabeled and unmodified particles. Numbers (1) and (2) indicate first and second replicate of $2 \mu \mathrm{m}$ particles.

\begin{tabular}{cccccc}
\hline & & $\mathbf{2 \mu M}$ & \multicolumn{2}{c}{$\mathbf{0 . 5} \boldsymbol{\mu M}$} \\
\hline & $\begin{array}{c}\text { Radiolabeled }{ }^{152} \mathrm{Eu} \\
(1)\end{array}$ & $\begin{array}{c}\text { Radiolabeled } \\
152 \mathrm{Eu}(2)\end{array}$ & Unmodified & $\begin{array}{c}\text { Radiolabeled } \\
{ }^{241} \mathrm{Am}\end{array}$ & Unmodified \\
\hline Effective Diameter (nm) & $1913 \pm 28$ & $1857 \pm 52$ & $1854 \pm 54$ & $657 \pm 5$ & $696 \pm 5$ \\
Half Width (nm) & $579 \pm 135$ & $914 \pm 65$ & $1090 \pm 35$ & $141 \pm 24$ & $248 \pm 29$ \\
Polydispersivity Index & $0.14 \pm 0.045$ & $0.25 \pm 0.029$ & $0.35 \pm 0.011$ & $0.06 \pm 0.015$ & $0.14 \pm 0.025$ \\
\hline
\end{tabular}

\subsubsection{Reproducibility and Robustness}

For reproducibility, another set of $2 \mu \mathrm{m}$ particles was radiolabeled with ${ }^{152} \mathrm{Eu}$, and a set of $0.5 \mu \mathrm{m}$ particles was labeled with ${ }^{241} \mathrm{Am}$ using the same method of first decomposing the nitrate salt, then coating with sodium silicate. For radiolabeled $0.5 \mu \mathrm{m}$ particles, no observable difference was seen compared to the unmodified particles (Fig. 3.C and Fig. A2), which was confirmed by dynamic light scattering (Table 1). Leaching into both tap water and soap solution was minimal $(0.26$ and $2.0 \%$, respectively), but slightly higher than for the $2 \mu \mathrm{m}$ particle radiolabeled with ${ }^{152} \mathrm{Eu}$ (Fig. 4). Rather than performing leaching studies for the second set of $2 \mu \mathrm{m}$ particles, the percent of the radioactivity removed within each wash was used as a comparison. This comparison allows for researchers to establish if particles are inert without performing separate leaching studies. There was good agreement in the percent activity removed in each wash between the two sets of $2 \mu \mathrm{m}$ particles and the $0.5 \mu \mathrm{m}$ particle radiolabeled with ${ }^{241} \mathrm{Am}$ (Fig. 4), while size determined by dynamic light scattering was also not significantly different (Table 1). The agreement between leaching/washing results and size led us to conclude that the method was reproducible.

To test the robustness of the radiolabeling and coating method, two trials were performed with slight modifications to ensure that small changes would still lead to particles with the desired characteristics. In the first, the particles were not washed in between the $\mathrm{Eu}\left(\mathrm{NO}_{3}\right)_{3}$ decomposition and silicate coating. In the second, the particles were spiked immediately after being decanted (no drying) with pore water present. After three repetitions of the mixing, sonicating, and drying process, the particles were still wet and were transferred to the crucible for heating. Leaching of the radiolabel from particles produced from both of these methods was not significantly different $(p<0.05)$ than particles produced from the original method. SEM imaging also revealed particles of the same size (Fig. A4). The only differences of note between the methods were that wet transferred particles produced only $50 \%$ mass yield (other methods had $80 \%$ mass yield), and the particles that were unwashed after the radiolabel baking had high activities in washes. 


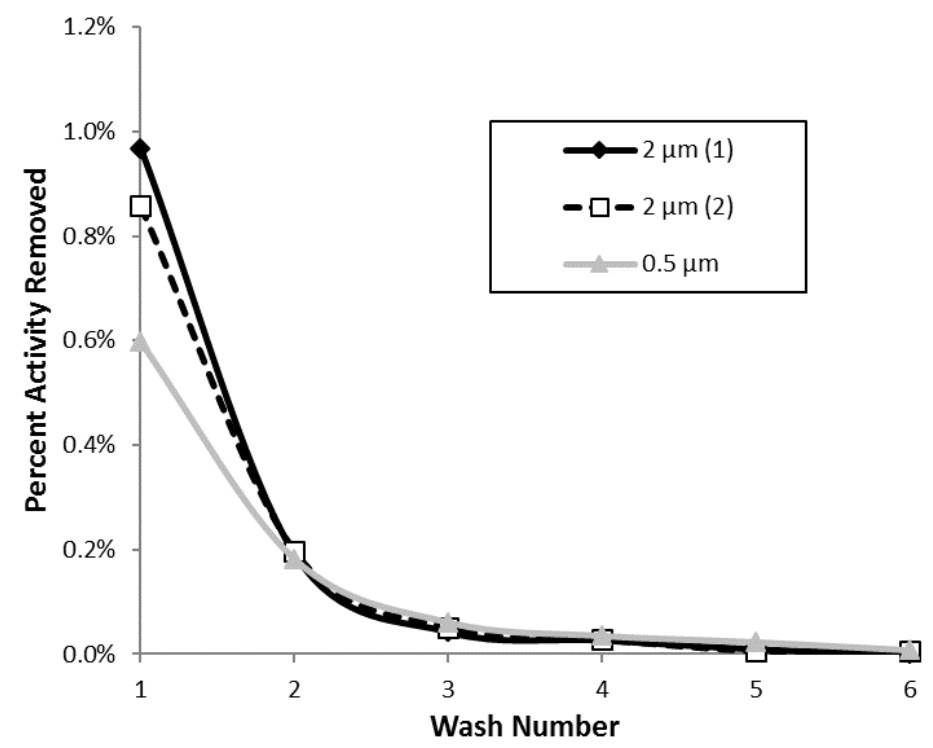

Figure 4. Percent activity removed in each wash for $2 \mu \mathrm{m}$ particle radiolabeled with ${ }^{152} \mathrm{Eu}$ (black diamonds), $2 \mu \mathrm{m}$ replicate (open squares), and $0.5 \mu \mathrm{m}$ particle radiolabeled with ${ }^{241} \mathrm{Am}$ (grey triangles).

\subsubsection{Further Leaching Studies into Aqueous Solution of Interest}

Overall, leaching into numerous aqueous solutions was minimal as the maximum percent leached was less than $4 \%$ of the activity within the samples. In addition to tap water and soap solution, leaching of the radiolabel was tested with four solutions for varying time periods. Leaching into two surrogate aqueous environments, artificial seawater and rainwater, was less than $2 \%$ for the $2 \mu \mathrm{m}$ particles labeled with ${ }^{152} \mathrm{Eu}$ and $0.5 \mu \mathrm{m}$ particles labeled with ${ }^{241} \mathrm{Am}$ after being mixed for $72 \mathrm{~h}$ (Fig. 5). The amount of leaching was slightly higher but not significantly different for $0.5 \mu \mathrm{m}$ particles compared to $2 \mu \mathrm{m}$ particles. Leaching into the most aggressive solution, $0.5 \mathrm{M} \mathrm{HNO}_{3}$, indicated that overall less than $4 \%$ of the radiolabel was available to be removed from the particle. Significantly more leaching ( $t$-test, $p>0.05$ ) was seen from the $0.5 \mu \mathrm{m}$ particles for nitric acid compared to leaching of ${ }^{152} \mathrm{Eu}$ from $2 \mu \mathrm{m}$ particles. The increased leaching from $0.5 \mu \mathrm{m}$ particles likely arises from two causes: 1) the longer half-life of ${ }^{241} \mathrm{Am}$ compared to ${ }^{152} \mathrm{Eu}$ requires more of the radionuclide to be added, possibly decreasing the fraction bound within the silica coating, and 2) the increased surface area of $0.5 \mu \mathrm{m}$ particles compared to $2 \mu \mathrm{m}$ particles decreases the thickness of the silica layer coated onto the particle (Table A1). However, we felt increasing the amount of sodium silicate was not possible as the predicted change in particle size would be greater than $1 \%$ (Table A1) and that less than $4 \%$ leaching is acceptable, especially in such an acidic solution. 


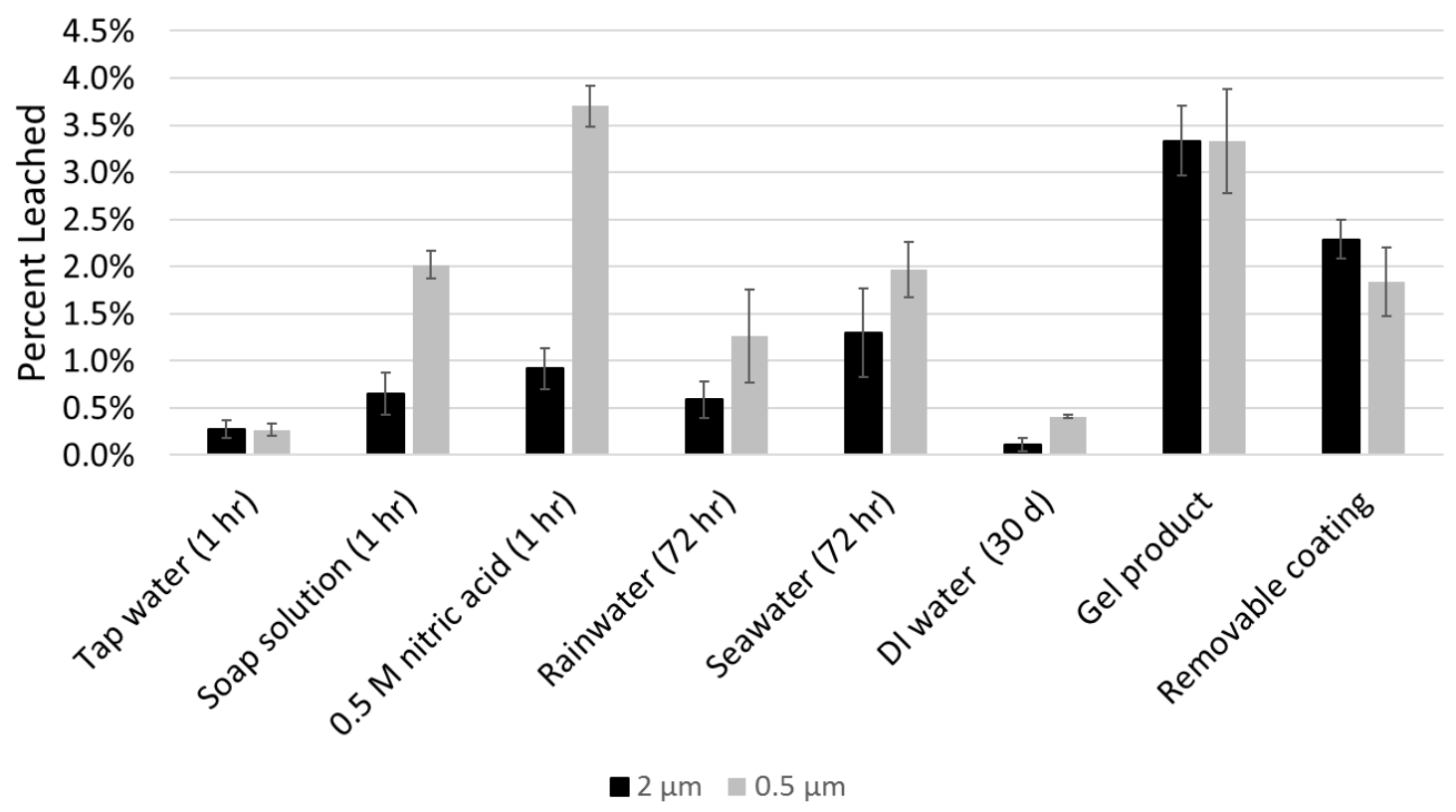

Figure 5. Percent of radiolabel that leached into tests solutions for $2 \mu \mathrm{m}$ particles radiolabeled with ${ }^{152} \mathrm{Eu}$ (black) and $0.5 \mu \mathrm{m}$ particles radiolabeled with ${ }^{241} \mathrm{Am}$ (grey).

Leaching into strippable decontamination agents was also tested to ensure that radiolabeled particles would adequately represent inert particles during other decontamination techniques. We tested particle leaching into two strippable decontamination agents while positive blanks established the percent of the radionuclide that could be recovered from each of the agents. We were able to recover $39 \%$ of the ${ }^{152} \mathrm{Eu}$ from the gel product and $20 \%$ from the removable coating. Recoveries of ${ }^{241} \mathrm{Am}$ were distinctly different than those of ${ }^{152} \mathrm{Eu}$, as $79 \%$ of the ${ }^{241} \mathrm{Am}$ was recovered from the gel product and only $7.9 \%$ was recovered from the coating. Determining the cause of this deviation was beyond the scope of this study. Even after accounting for the amount of radionuclide able to be recovered, leaching into the strippable agent was estimated at a maximum of $3.33 \%$ of the radiolabel leaching into solution (Fig. 5). The activity within the gel product with $0.5 \mu \mathrm{m}$ particles was much higher than that of other samples, a finding we attributed to incomplete settling of the particles due to the higher viscosity of the dissolved gel product. Both the sample containing particles and the positive blank were filtered, revealing similar percent leaching of $2 \mu \mathrm{m}$ particles. Overall, leaching into the strippable agent was similar to that of the aqueous solution tested.

\subsection{Conclusions}

The low amount of leaching observed makes these coated particles, or particles coated in a similar way, ideal for use in both environmental fate and decontamination studies. The use of trivalent elements allows for a large number of radionuclides that could be substituted within the crystal coating depending on the desired application. For instance, ${ }^{140}$ La could be utilized if true environmental transport/decontamination studies are required as the 1.6 day half-life 
would quickly return the dose to background levels. Alternatively, ${ }^{151} \mathrm{Gd}\left(\mathrm{t}_{1 / 2}=124\right.$ days) or ${ }^{125} \mathrm{Sb}$ (2.7 years) could be used for intermediate time periods and ${ }^{152} \mathrm{Eu}$ (13.7 years) and ${ }^{241} \mathrm{Am}$ (432 years) as long-lived nuclides. Since little difference in leaching was seen between ${ }^{152} \mathrm{Eu}$ and ${ }^{241} \mathrm{Am}$, the decay mode of the nuclide does not seem to have an effect, and either alpha- or betaemitting nuclides can be used. With this abundance of radionuclides, the robustness and reproducibility of the method, and the minimal leaching displayed, this labeling procedure of first depositing the radionuclide as a nitrate salt, decomposed to a sesquioxide, and finally coating it with sodium silicate is a promising means to create inert silica particles for use in decontamination and environmental transport studies. 


\subsection{Particle Application Method}

We needed a reproducible and representative method to deposit particles uniformly on the test surfaces. We began with acyclic coupons since that size is the easiest to work: tire coupons are rather thick and curved, while painted coupons are quite thin. Three methods of accomplishing uniform surface coverage were tested. First, the particles were suspended in ethanol, and $100 \mu \mathrm{l}$ of the solution was spiked onto the surface (0.8-1 mg added to surface). The resulting coverage was uniform as the low surface tension of ethanol allowed the particles to spread over the surface and deposit quickly (Fig. 6A). For the second application method, the coupons were pressed into the particles within a Petri dish. For consistency, a lead brick was used to apply constant pressure to the coupon as it was pressed into $2 \mathrm{mg}$ of particles within the dish. The coupons were pressed for a total of $5 \mathrm{~min}$ while rotating the coupon a quarter turn every minute. The resulting surface coverage was considerably clumped (Fig. 6B), and 0.5-0.8 mg of particles was applied to the surface. The final method used water instead of ethanol to apply the particle to the surface. The high surface tension of water causes the particles to be contained within drops, leading to some particle clumping (Fig. 6C).

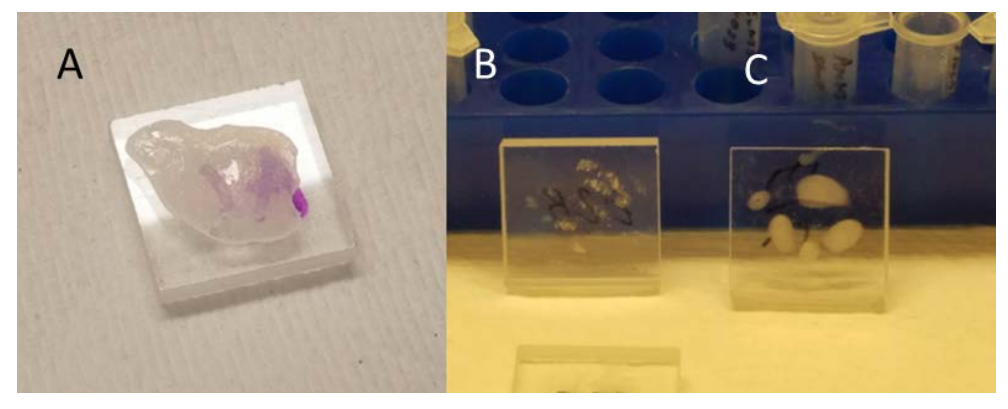

Figure 6. Particles applied to an acrylic coupon: (A) using an ethanol spike, (B) pressing the coupon into the powder, and (C) using a water spike.

After visual inspection of the surface coverage, the coupons were wrapped in plastic, placed in sealable bags, counted on an Ortec Detective, and allowed to sit overnight. StripCoat TLC was then applied to the surface by using a soft bristle paint brush. The polymer was allowed to dry for 24 hours before being stripped off, and the coupons recounted.

A slight difference was seen in particle removals between the three application methods. The highest removals were seen for particles applied by pressing the coupon into a powder, followed by spiking with water and ethanol in that order (Fig. 7). This order corresponds to the amount of clumping on the surface, where the more clumped the particles are, the higher the removals. The particles within large clumps are interacting with each other rather than the surface, decreasing the effect of surface interactions and increasing removal. Therefore, we concluded that ethanol was the most representative method of a uniform surface coverage. Further, the uniform coverage resulting from the ethanol spike led to the smallest error (standard 
deviation of triplicate removals). Therefore, ethanol was deemed to be the more representative and reproducible method.

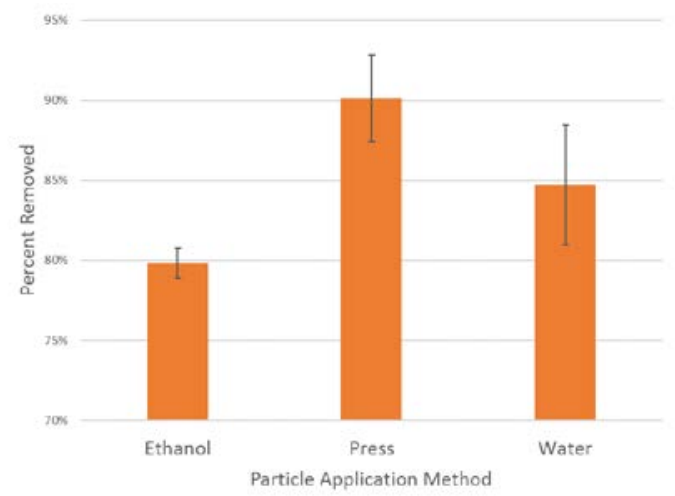

Figure 7. Removals of particle from an acrylic coupon using StripCoat TLC. The results generally follow the amount of surface clumping. Error bars represent the standard deviation of triplicate measurements. 


\subsection{Positive Blanks and the Potential for Cross-contamination}

\subsection{Positive Blanks}

A set of coupons was spiked with ${ }^{137} \mathrm{Cs}$ and subjected to the same counting procedure to ensure that the applied decontamination method was the only source of ${ }^{137} \mathrm{Cs}$ loss from the coupons. After a spiking and drying procedure (in triplicate) analogous to that used for other tests, coupons of tire, gray paint, white paint, and acrylic were wrapped in plastic, bagged in plastic sealable bags, analyzed for initial counts of ${ }^{137} \mathrm{Cs}$ on a Ortec Detective DX-100, and allowed to sit for 24 hours. The coupons were then removed from the bags and plastic wrap and allowed to sit for 24 hours, re-bagged, and re-counted ("bagging stage"). Once counted, the samples were removed from the bags, brushed with the same brushes used to apply the strippable decontamination agents, allowed to sit for another 24 hours, bagged, and analyzed for final counts ("brushing stage"). The contamination remaining on each coupon was then calculated after the "bagging" and "brushing" stages.

Little ${ }^{137} \mathrm{Cs}$ was removed during the bagging stage as all coupons retained over $95 \%$ of the initial contamination, while after the brushing stage, some removal was seen for all coupon types. Wrapping and bagging the coupons were performed to reduce the amount of ${ }^{137} \mathrm{Cs}$ removed during the counting process. Therefore, it was expected that most of the contamination would still be on the coupons after the bagging stage. Indeed, $99 \%$ of the initial contamination remained on the coupons for tire, white paint, and acrylic surfaces. A small amount of ${ }^{137} \mathrm{Cs}$ was removed from the gray painted coupons as $95 \%$ of the contamination remained after bagging and counting the coupons. However, this small amount of contamination removed indicates that the decontamination methods are the dominant source of removal, and any losses during the counting processes can mostly be neglected. On the other hand, some ${ }^{137} \mathrm{Cs}$ was removed when the coupons were brushed. Brushing the coupon surface seemingly resulted in some physical removal of deposited ${ }^{137} \mathrm{Cs}$, and the trend in overall percentages remaining across coupon types followed tire $>$ acrylic $>$ grey paint $>$ white paint (Fig. 8). However, at most, brushing removed $25 \%$ of the deposited ${ }^{137} \mathrm{Cs}$, indicating that decontamination agents are needed to remove wet deposited ${ }^{137} \mathrm{Cs}$ from the surfaces. In addition, a strippable coating was brushed onto the surface so the naked bristles did not contact the surface directly. As a result, we expect that this control experiment represents a conservative estimate of the amount that may be removed during the normal application of a stripping agent onto the coupon surfaces. 


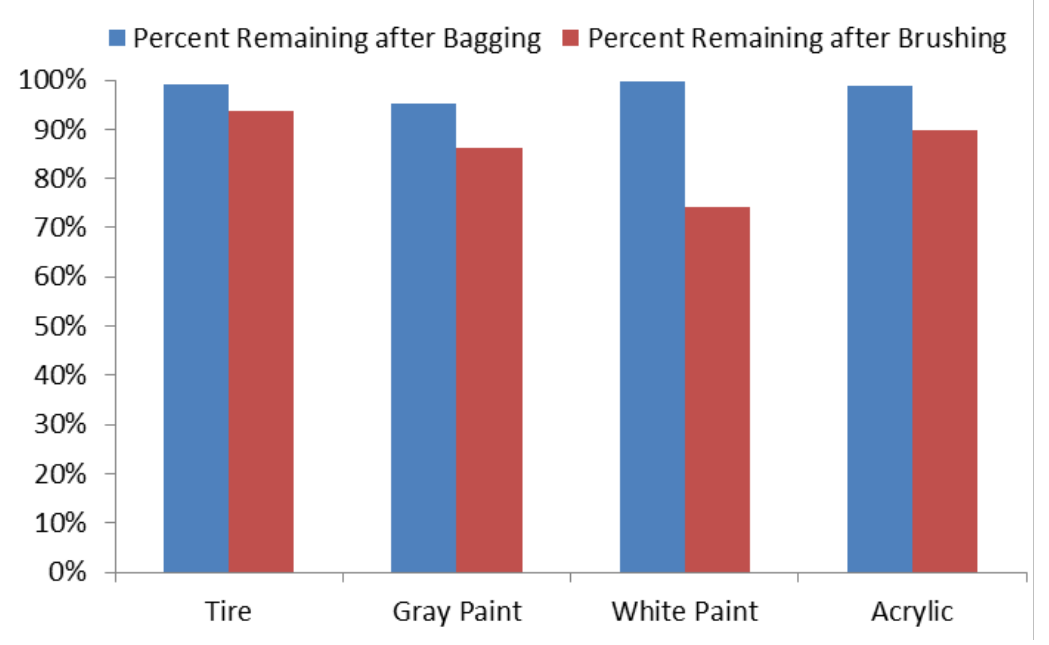

Figure 8. Percentage of counts remaining of coupon surfaces after bagging state (blue) and brushing stage (red) for tire, gray painted, white painted, and acrylic coupons.

\subsection{Potential for Cross-contamination and Negative Blanks}

Limited potential for cross-contamination was seen between individual coupons. To determine the potential for cross-contamination, three white painted coupons were spiked with ${ }^{137} \mathrm{Cs}$ next to three uncontaminated coupons. All coupons were dried, bagged, and counted, alternating between spiked and uncontaminated coupons. After being allowed to sit for 24 hours, coupons were then removed from the bags, and DeconGel Pro was applied to each surface by using the same brush, again alternating between spiked and uncontaminated coupons. DeconGel Pro was selected because it was difficult to apply and because it displayed the lowest amount of retention of ${ }^{137} \mathrm{Cs}$ within the films, indicating the possibility for cross-contamination. DeconGel Pro was then allowed to dry overnight and peeled off in the morning ( $20 \mathrm{~h}$ later). Both the coupons and removed films were analyzed for final counts. For all contaminated coupons, over 99\% removal of ${ }^{137} \mathrm{Cs}$ was achieved, while no ${ }^{137} \mathrm{Cs}$ was detected on the previously uncontaminated surfaces. Within the films of the contaminated samples, $60 \%$ of the removed ${ }^{137} \mathrm{Cs}$ was retained. Some of the ${ }^{137} \mathrm{Cs}\left(4 \%\right.$ of the total deposition ${ }^{137} \mathrm{Cs}$ ) was detected in the films of the uncontaminated coupons, indicating that the application of DeconGel Pro can remove ${ }^{137} \mathrm{Cs}$ and deposit within the film on another surface. However, consistent with the non-detection of ${ }^{137} \mathrm{Cs}$ on the uncontaminated surfaces, the ${ }^{137} \mathrm{Cs}$ is unlikely to leave the film and deposit on the surface itself as the only transport mechanism of cesium ions to the surface would be the slow diffusion though the highly viscous film. This slow transport, coupled with the low concentrations detected within the films, led us to conclude that little cross-contamination of the coupon surfaces is possible. 


\subsection{Static Test Kinetics}

\subsection{Methods}

Tests of the aqueous wash solutions, tap water, and SSDX-12 aircraft cleaner were first performed in static, no-flow environments. For SSDX-12, the concentrated reagent solution is recommended to be diluted in water from 1:4 to $1: 15$ by volume of SSDX-12 to water for biological and chemical decontaminations. A ratio of 1:4 was used for these experiments.

To define the governing kinetics in static tests, the removal of ${ }^{137} \mathrm{Cs}$ as a function of time was studied. One-square-inch coupons of acrylic, high-gloss paint (white), low-gloss paint (grey), and tire rubber were spiked with $200 \mu \mathrm{L}$ of solution containing approximately $2000 \mathrm{cpm}$ of ${ }^{137} \mathrm{Cs}$. Coupons were allowed to dry, analyzed for initial counts (Ortex Detective DX-100), and aged for $24 \mathrm{~h}$. Coupons were then placed contaminated side down on 3-mm glass beads in a Petri dish containing $10 \mathrm{~mL}$ of the wash solutions. Placing the coupons on beads ensured that most, if not all, of the contaminated surface was exposed to the wash solution, rather than being flush with the bottom of the dish. For tire coupons, $10 \mathrm{~mL}$ was not adequate to fill the treads; therefore, an additional $5 \mathrm{~mL}$ of wash solution was added. Next, $100 \mu \mathrm{L}$ aliquots were taken from the wash solution at 2, 5, 10, 20, 30, 60, 90, 120, and $180 \mathrm{~min}$ from coupon exposure to the wash solution. An additional aliquot was taken at $45 \mathrm{~min}$ for the SSDX-12 decontamination test. Aliquots were counted for 10 min on the Wiz-2 gamma counter (Perkin Elmer) for ${ }^{137} \mathrm{Cs}$. After the final aliquot was taken, the coupons were removed from the solution, blotted dry, and counted for final ${ }^{137} \mathrm{Cs}$ (Detective).

\subsection{Results}

Cesium removal kinetics were similar between tap water and the SSDX-12 solution, though overall removals were quite different between the two wash solutions (Fig. 9). Cesium radioactivity in the wash solutions generally followed the same pattern as a function of time for all experiments, as for each surface-wash solution pair the radioactivity plateaued at $60 \mathrm{~min}$. The magnitude of ${ }^{137} \mathrm{Cs}$ for each wash solution closely mirrored the overall removals of ${ }^{137} \mathrm{Cs}$ from the surface. Percent removals from surfaces followed the trend: acrylic $\approx$ high gloss paints $>$ low gloss paint > tires, which is consistent with removals using strippable decontamination agents. Removals from acrylic and high gloss paint coupons were $>99 \%$ for both tap water and SSDX-12 solution. The use of SSDX-12 increased percent removals from tires over $100 \%$, as $40 \%$ and $80 \%$ removals were seen for tap water and SSDX-12, respectively. Conversely, low gloss paint displayed no increase in removals from tap water to SSDX-12 solution ( $\approx 80 \%$ ), though more replicates are needed before overall conclusions can be reached. Since removals of ${ }^{137} \mathrm{Cs}$ for both tap water and SSDX-12 solutions reached pseudo-equilibrium after $1 \mathrm{hr}$, static experiments will now be performed for $1 \mathrm{hr}$ with no aliquot testing to minimize labor intensity in collecting replicates. 

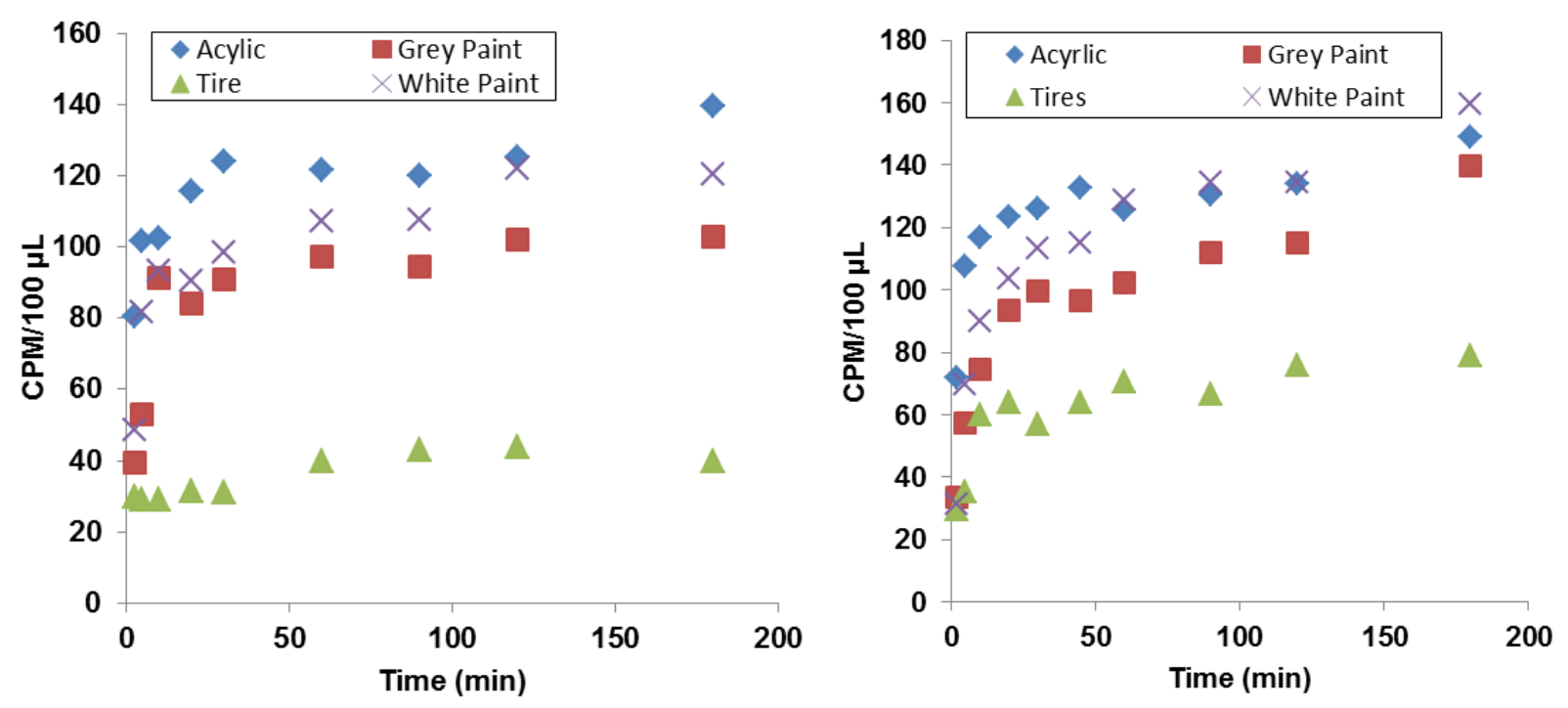

Figure $9 .{ }^{137} \mathrm{Cs}$ activity (cpm) in the wash solutions for tap water (left) and SSDX-12 (right) 


\subsection{Removal Comparison}

\subsection{Methods}

\subsubsection{Application/Blanks}

Coupons of acrylic, tire, and painted (high and low gloss) aluminum surfaces were cleaned by using soap and water to remove any dust or byproducts from the cutting process, rinsed five times with deionized water $(18 \mathrm{M} \Omega)$, and allowed to dry overnight. ${ }^{137} \mathrm{Cs}$ was exposed to coupons in triplicate by pipetting $200 \mu \mathrm{L}$ of solution containing approximately $2000 \mathrm{cpm}$ of ${ }^{137} \mathrm{Cs}$ in deionized water onto the surface. Radiolabeled particles ( 2 and $0.5 \mu \mathrm{m}$ ) suspended in $99.5 \%$ pure ethanol were applied to the surface of the coupons. Targeted particle contamination was 0.8-1 mg and 300 to $600 \mathrm{cpm}$ on the Ortec Detective. Coupons were dried for $2 \mathrm{~h}$ so that all visible water and ethanol had evaporated. They were then wrapped in plastic and analyzed on an Ortec Detective gamma spectrometer for five minutes to establish an initial count. Mixed contamination was simulated by spiking ${ }^{137} \mathrm{Cs}$ in deionized water, followed by the $0.5 \mu \mathrm{m}$ then $2 \mu \mathrm{m}$ particles. After each of these spikes, the samples were allowed to dry for $2 \mathrm{~h}$ before the next exposure. A set of control samples was prepared for each contamination type: ${ }^{137} \mathrm{Cs}, 2 \mu \mathrm{m}$ particles, $0.5 \mu \mathrm{m}$ particles, and mixed contamination. These samples were dried, wrapped, bagged, aged overnight, and unwrapped to determine the fraction of contamination remaining after unwrapping. This set served as negative blanks.

\subsubsection{Strippable Coatings}

Strippable decontamination agents were brushed onto the coupon surface to at least the minimum recommended thickness by the manufacturer. The film thicknesses were $40,50,10$, and 4 mils for DeconGel Pro, StripCoat TLC Free, DeconCoat, and SprayLat, respectively. Samples were then allowed to dry overnight (at least 18 hours) before the films were removed. DeconGel Pro, StripCoat TLC Free, and DeconCoat films were able to be removed by simply peeling the agent off the surface, and these films were saved for gamma counting. Coupons were then bagged and recounted. The agents were then reapplied two more times to cesium-only contaminated surfaces, following the same curing and counting process. Films from the second and third decontamination were not saved for counting. After the third decontamination, the samples sat for 10 days (two weeks from initial contamination) before a second contamination of ${ }^{137} \mathrm{Cs}$ was performed. This contamination mimicked the initial contamination, though only a single decontamination was performed. A visual log of the strippable coating application and removal is given in Appendix 3.

\subsubsection{Static Tests}

Triplicate coupons were then placed contaminated side down on 3-mm glass beads in a Petri dish containing $10 \mathrm{~mL}$ of the wash solutions. Placing the coupons on beads ensured that most, if not all, of the contaminated surface was exposed to the wash solution, rather than being flush with the bottom of the dish. For tire coupons, $10 \mathrm{~mL}$ was not adequate to fill the treads; 
therefore, an additional $5 \mathrm{~mL}$ of wash solution was added. After one hour the coupons were removed from the solution, blotted dry, and analyzed for final count (Detective).

\subsubsection{Flow Tests}

In flow tests, $500 \mathrm{~mL}$ of solution (either tap water or 4:1 ratio of tap water to SSDX-12) was passed at $100 \mathrm{~mL} / \mathrm{min}$ over the contaminated surface of the coupon set in a holder positioned at $45^{\circ}$. The coupons were counted on the Ortec before and after to determine removals. Tests were visually monitored to ensure the entire surface was exposed to the wash solution - when required the nozzle was repositioned to increase surface coverage of the wash solution.

\subsubsection{Removal Quantification}

To quantify the effectiveness of an agent to remove radioactivity, the percent removal was calculated:

$$
\text { Percent Removal }=\frac{\text { Final } C P M}{\left(\text { Initial } C P M \times f_{b}\right)} \times 100
$$

where the "Initial CPM" refers to the counts per minute of ${ }^{137} \mathrm{Cs}$ before the agent was applied, $f_{b}$ to the fraction remaining on the blanks, and "Final CPM" refers to the counts per minute after the films were removed. For the second and third decontamination, Initial CPM is the Final CPM of the previous trial. To quantity the amount of ${ }^{137} \mathrm{Cs}$ retained within the films, a "Percent Retained" was calculated:

Percent Retained $=\frac{C P M \text { in Film }}{\left(\text { Initial } C P M \times f_{b}\right)-\text { Final CPM }} \times 100$.

\subsection{Results}

\subsubsection{Removal Comparison}

The magnitude of removal was dependent on the type of contamination, as ${ }^{137} \mathrm{Cs}$ was removed most readily followed by $2 \mu \mathrm{m}$ then $0.5 \mu \mathrm{m}$ particles. For ${ }^{137} \mathrm{Cs}$, removals were very high on all surfaces for all decontamination types except flowing tap water over rough surfaces (Fig. 10). Removals decreased in flow tests for tap water down to $60 \%$ and $30 \%$ for low gloss grey paint and tire surfaces, respectively. As such, tap water may not be adequate for removing soluble cesium for aircraft, though aircraft soap solution and strippable agents show remarkably high removals. For both 2 and $0.5 \mu \mathrm{m}$ particles, there is a distinct difference between removals using the strippable agents and those of the aqueous decontamination solutions (soap and tap water). Relatively high removals of $2 \mu \mathrm{m}$ particles (70\%-100\%) and $0.5 \mu \mathrm{m}$ particles (50\%-90\%) were achieved with the strippable decontamination techniques, while little contamination was removed using both solutions in static and flowing environments. As such, the removal of particulates from aircraft required the use of strippable agents. No significant difference (t-test, $p>0.05$ ) was seen between the strippable agents with the exception of the slightly lower removals of particles using StripCoat on acrylic. 


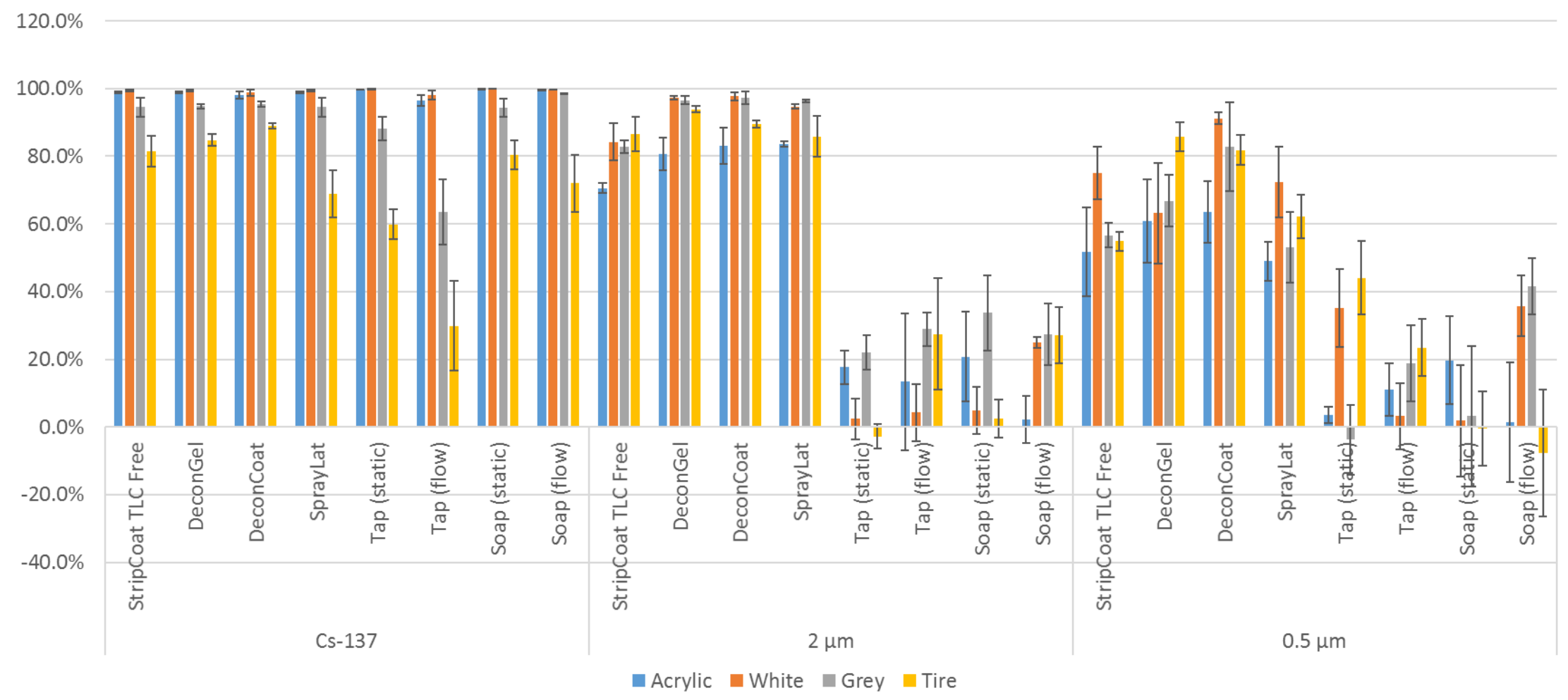

Figure 10. Percent removals of ${ }^{137} \mathrm{Cs}, 2 \mu \mathrm{m}$ particles, and $0.5 \mu \mathrm{m}$ particles from acrylic (blue), white painted (orange), grey painted (grey), and tire (yellow) coupon surfaces using StripCoat TLC free, DeconGel, DeconCoat, and SprayLat strippable agents, as well as tap water and soap solution (4:1 ratio of tap water to SSDX-12) in both static and flow tests. 


\subsubsection{Film Retention}

The retention of contamination within the films gives insight into the effectiveness of the strippable agent and ensures that removal within the agent is the dominant removal mechanism. Retention of particles within the films was generally high, while distinctly lower retentions were seen for ${ }^{137} \mathrm{Cs}$ (Fig. 11). In addition, ${ }^{137} \mathrm{Cs}$ was especially not well retained in the films from surfaces to which ${ }^{137} \mathrm{Cs}$ does not strongly bond (acrylic and high gloss/white paint). The low affinity for the surface of ${ }^{137} \mathrm{Cs}$, as evidenced by the high removals, may allow ${ }^{137} \mathrm{Cs}$ to be removed during the application of the strippable agent. As such, the ${ }^{137} \mathrm{Cs}$ not retained in the film could have been either attached to the application brush or dissolved in droplets of wet strippable agent that ran off the surface and attached to the benchtop. The recovery of particles, on the other hand, was generally around $100 \%$ ( $t$-test, $p>0.05$ ). The higher affinity of both $2 \mu \mathrm{m}$ and $0.5 \mu \mathrm{m}$ particles for the surface compared to ${ }^{137} \mathrm{Cs}$ makes the physical stripping of the film the dominant removal mechanism, leading to high recoveries.

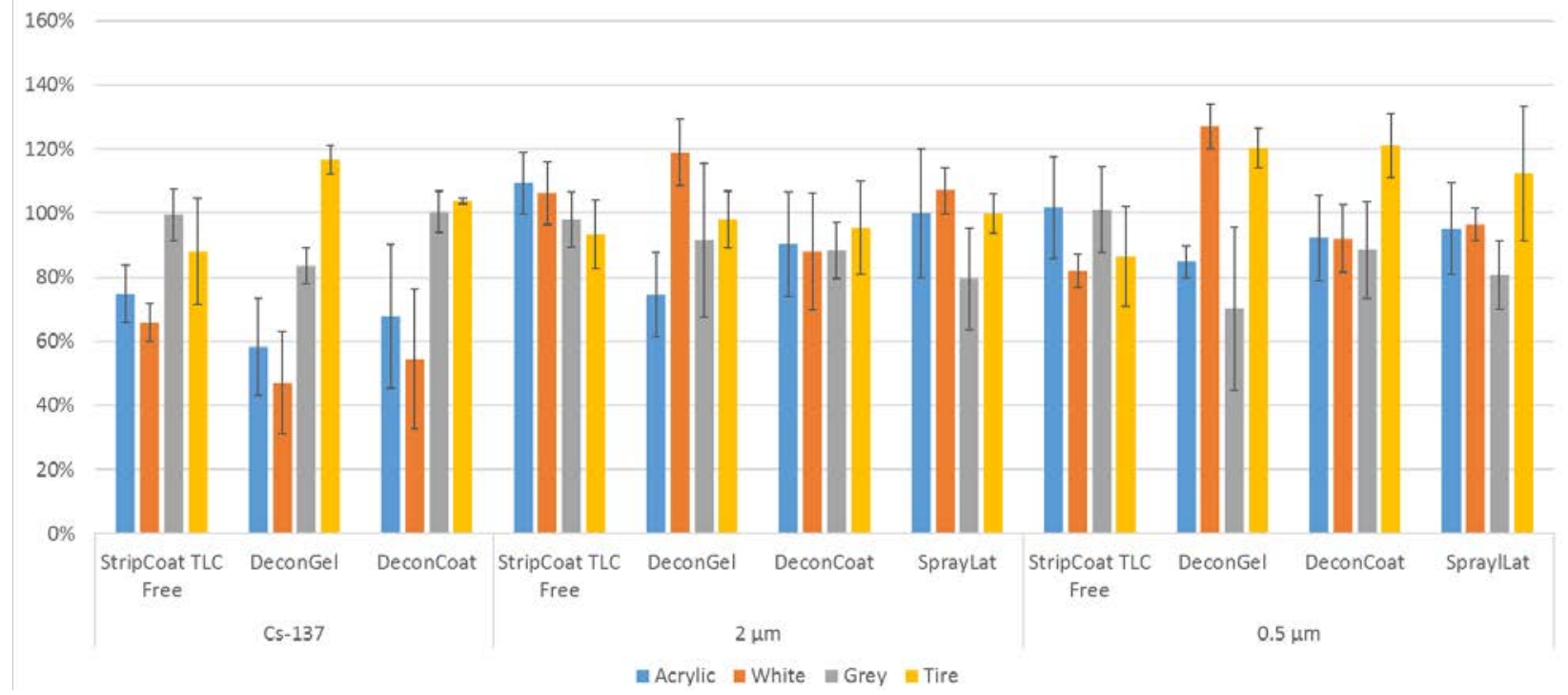

Figure 11. Percent of ${ }^{137} \mathrm{Cs}, 2 \mu \mathrm{m}$ particles, and $0.5 \mu \mathrm{m}$ particles retained in the films of strippable agents when removed from acrylic (blue), white painted (orange), grey painted (grey), and tire (yellow) coupon surfaces. Note: Recoveries of ${ }^{137} \mathrm{Cs}$ in SprayLat were not determined due to flaking of the agent after drying. 


\subsubsection{Multiple Decontaminations and Second Cesium Contamination Event}

Subsequent decontaminations displayed distinctly lower removal percentages compared to the initial values (Fig. 12). This decrease is likely the result of the high percent removed in the initial decontamination, the lower concentration of cesium on the surface, and the increased likelihood that the remaining cesium ions are oriented with the few high-energy sorption sites thereby increasing the energy of interaction and decreasing the removal percentage. The high initial removal percentages make multiple decontaminations not a primary concern, as residual exposures to personnel after the initial decontamination would be quite low.

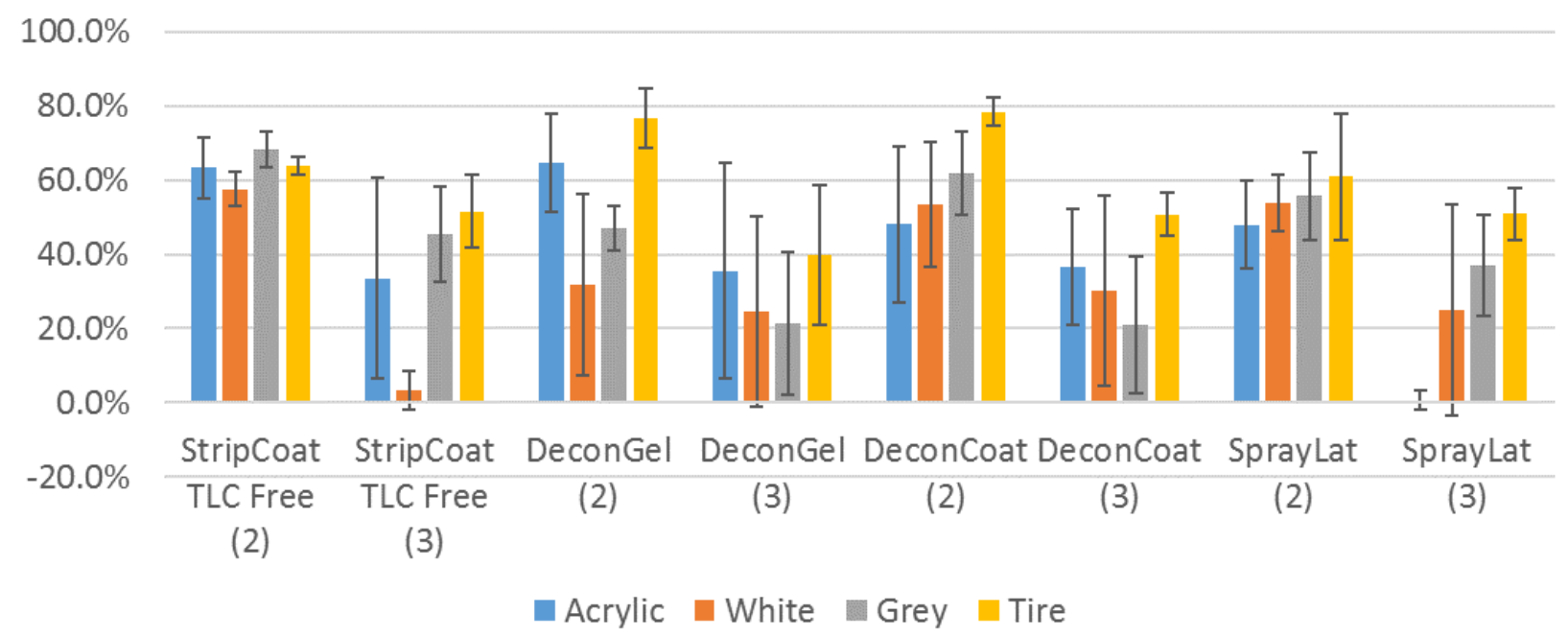

Figure 12. Percent removals after secondary (2) and tertiary (3) applications of strippable decontamination agents from acrylic (blue), white painted (orange), grey painted (grey), and tire (yellow) coupon surfaces.

Removal percentages after the second contaminations of acrylic and high gloss paint surfaces were generally very similar to those of the initial decontaminations. Removal was greater than $98 \%$ for all methods/agents except for DeconGel on acrylic and grey paint and SprayLat on tire (Fig. 13). This decrease in effectiveness may be due to the tackiness of DeconGel, thereby altering the surface by leaving a film/residue ${ }^{1}$ on the coupon face, which provides more sorption sites for cesium to adhere to the surface. Therefore, DeconGel may be less suitable in comparison to other methods for decontamination of acyclic and gray painted aluminum surfaces when multiple exposures are possible. Similarly, residues left behind by the incomplete removal of SprayLat on dark tire surfaces may decrease removals for a second contamination event, making SprayLat ill-suited to decontaminate tires unless measures are taken to remove this residue.

${ }^{1} \mathrm{~A}$ thorough washing and scrubbing of the surface with an appropriate cleaner may eliminate this residue. 


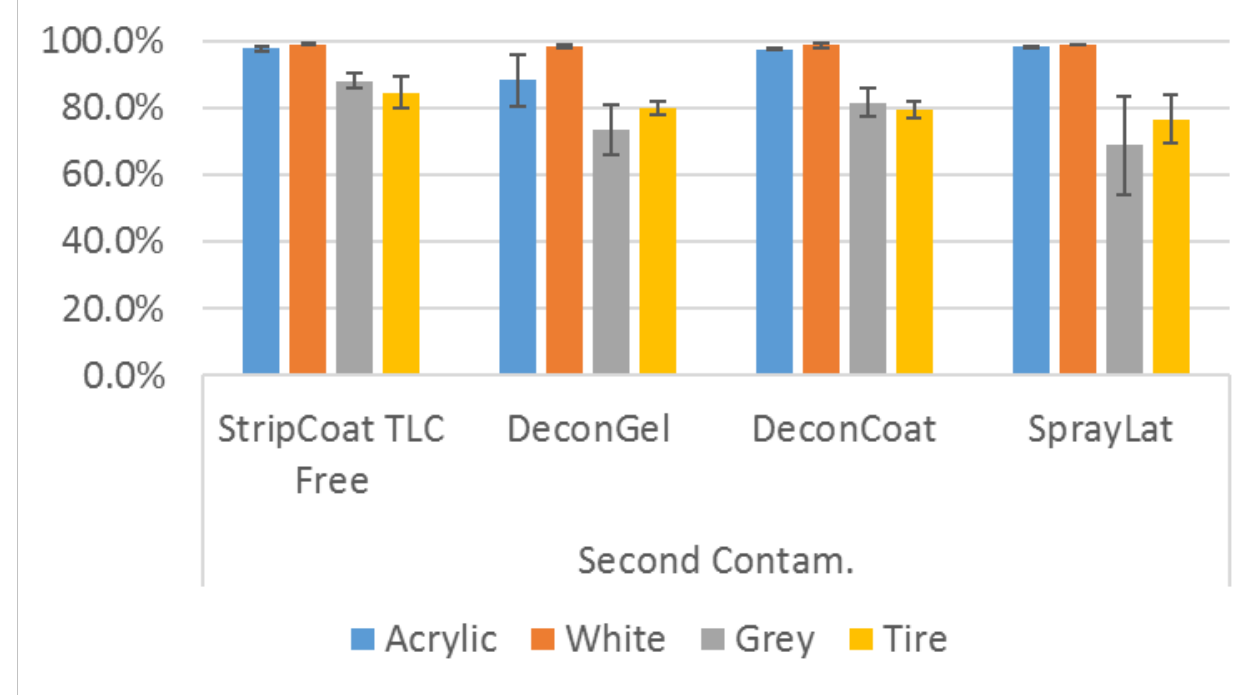

Figure 13. Percent removals after a second contamination event by strippable decontamination agents from acrylic (blue), white painted (orange), grey painted (grey), and tire (yellow) coupon surfaces.

\subsubsection{Mixed Contamination}

Removals of ${ }^{137} \mathrm{Cs}, 2 \mu \mathrm{m}$ particles, and $0.5 \mu \mathrm{m}$ particles in a mixture on the surface were similar to removals when each type of contamination was spiked onto the surface alone (Fig. 14). The only observed difference was the slight increase in removals of $2 \mu \mathrm{m}$, which were the last contamination type to be spiked on this surface and, as a result, spiked onto $0.5 \mu \mathrm{m}$ particles. As such, this increase does not signify that removals are higher for contamination present in a mixture but that surface coverage effects may be present. The decreased contact with the surface and more particle-to-particle interactions led to higher removals consistent with the results seen in the application trials. Therefore, the presence of multiple contamination types does not seem to effect removals if surface coverage is kept constant. Further, if higher surface coverages of particulates are present, removals are expected to be higher. 


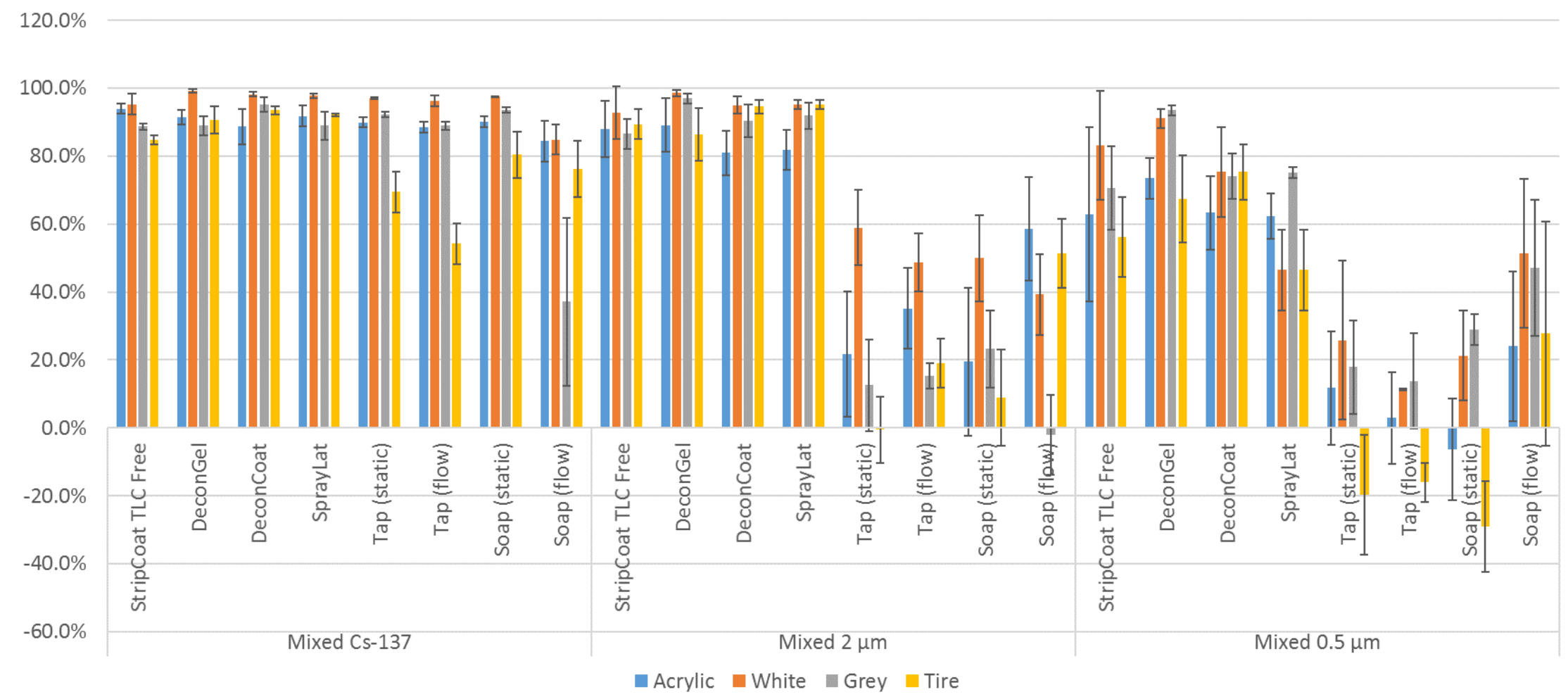

Figure 14. Percent removals of mixed contamination containing ${ }^{137} \mathrm{Cs}, 2 \mu \mathrm{m}$ particles, and $0.5 \mu \mathrm{m}$ particles from acrylic (blue), white painted (orange), grey painted (grey), and tire (yellow) coupon surfaces using strippable agents (StripCoat TLC free, DeconGel, DeconCoat, and SprayLat), as well as tap water and soap solution (4:1 ratio of tap water to SSDX-12) in both static and flow tests. 


\subsection{Recommendations}

The ineffectiveness of solution-based decontamination agents in removing particulate far-field fallout makes them less effective for use in response to radiological contamination incidents, where both particles and soluble radionuclides are present. If the contamination is deemed to be only soluble cesium deposited wet on the aircraft surface, then soap solution (4:1 ratio of tap water to SSDX-12) can be applied for effective decontamination. However, if radioactive particles are present on the surface, then the use of strippable decontamination agents is advised. Little difference was seen in the overall removals between strippable decontamination agents, suggesting that if each can be applied adequately to the surface (i.e., uniform coverage at recommended thickness with little dripping), then any of the strippable decontamination agents will be effective in removing both soluble radionuclides and radioactive particles from Naval aircraft surfaces tested. 


\subsection{References}

[1] G. Furuki, J. Imoto, A. Ochiai, S. Yamasaki, K. Nanba, T. Ohnuki, B. Grambow, R.C. Ewing, S. Utsunomiya, Caesium-rich micro-particles: A window into the meltdown events at the Fukushima Daiichi Nuclear Power Plant, Scientific Reports, 7 (2017) 42731.

[2] N. Yamaguchi, M. Mitome, A.-H. Kotone, M. Asano, K. Adachi, T. Kogure, Internal structure of cesium-bearing radioactive microparticles released from Fukushima nuclear power plant, Scientific Reports, 6 (2016) 20548.

[3] Y. Abe, Y. lizawa, Y. Terada, K. Adachi, Y. Igarashi, I. Nakai, Detection of uranium and chemical state analysis of individual radioactive microparticles emitted from the Fukushima nuclear accident using multiple synchrotron radiation X-ray analyses, Analytical Chemistry, 86 (2014) 8521-8525.

[4] K. Adachi, M. Kajino, Y. Zaizen, Y. Igarashi, Emission of spherical cesium-bearing particles from an early stage of the Fukushima nuclear accident, Scientific Reports, 3 (2013) 2554.

[5] M. Kaltofen, A. Gundersen, Radioactively-hot particles detected in dusts and soils from Northern Japan by combination of gamma spectrometry, autoradiography, and SEM/EDS analysis and implications in radiation risk assessment, Science of the Total Environment, 607 (2017) 1065-1072.

[6] J. Imoto, A. Ochiai, G. Furuki, M. Suetake, R. Ikehara, K. Horie, M. Takehara, S. Yamasaki, K. Nanba, T. Ohnuki, Isotopic signature and nano-texture of cesium-rich micro-particles: Release of uranium and fission products from the Fukushima Daiichi Nuclear Power Plant, Scientific Reports, 7 (2017) 5409.

[7] N. Kaneyasu, H. Ohashi, F. Suzuki, T. Okuda, F. Ikemori, Sulfate aerosol as a potential transport medium of radiocesium from the Fukushima nuclear accident, Environmental Science \& Technology, 46 (2012) 5720-5726.

[8] K. Tanaka, Y. Takahashi, A. Sakaguchi, M. Umeo, S. Hayakawa, H. Tanida, T. Saito, Y. Kanai, Vertical profiles of iodine-131 and cesium-137 in soils in Fukushima Prefecture related to the Fukushima Daiichi Nuclear Power Station accident, Geochemical Journal, 46 (2012) 73-76.

[9] H. Malá, P. Rulík, V. Bečková, J. Mihalík, M. Slezáková, Particle size distribution of radioactive aerosols after the Fukushima and the Chernobyl accidents, Journal of Environmental Radioactivity, 126 (2013) 92-98.

[10] L. Devell, H. Tovedal, U. Bergström, A. Appelgren, J. Chyssler, L. Andersson, Initial observations of fallout from the reactor accident at Chernobyl, Nature, 321 (1986) 192-193.

[11] J. Tschiersch, B. Georgi, Chernobyl fallout size distribution in urban areas, Journal of Aerosol Science, 18 (1987) 689-692. 
[12] C. Adams, N. Farlow, W. Schell, The compositions, structures and origins of radioactive fallout particles, Geochimica et Cosmochimica Acta, 18 (1960) 42IN351IN553IN755350IN452IN65456.

[13] J.S. Brown, T. Gordon, O. Price, B. Asgharian, Thoracic and respirable particle definitions for human health risk assessment, Particle and Fibre Toxicology, 10 (2013) 12.

[14] A. Stohl, P. Seibert, G. Wotawa, D. Arnold, J. Burkhart, S. Eckhardt, C. Tapia, A. Vargas, T. Yasunari, Xenon-133 and caesium-137 releases into the atmosphere from the Fukushima Dai-ichi nuclear power plant: Determination of the source term, atmospheric dispersion, and deposition, Atmospheric Chemistry and Physics, 12 (2012) 2313-2343.

[15] K. Larson, J. Neel, H. Hawthrone, H. Mork, R. Rowland, Operation Plumbbob: Distribution, Characteristics, and Biotic Availability of Fallout, WT-1488 (1966) .

[16] R. Pöllänen, I. Valkama, H. Toivonen, Transport of radioactive particles from the Chernobyl accident, Atmospheric Environment, 31 (1997) 3575-3590.

[17] C.F. Miller, The Radiological Assessment and Recovery of Contaminated Areas, Naval Radiological Defense Laboratory, San Francisco, CA (1958).

[18] B. Fish, T. Clark, R. Boyett, W. Wilkie Jr, J. Thompson, Environmental Studies: Radiological Significance of Nuclear Rocket Debris, Progress Report, July 1, 1965-June 30, 1966, Oak Ridge National Laboratory (1966).

[19] U.S. EPA, Evaluation of Low-Tech Indoor Remediation Methods Following Wide Area Radiological/Nuclear Incidents, U.S. Environmental Protection Agency, Washington, DC (2017).

[20] S. Brandriss, G. Borchardt, J. Kreuter, S. Margel, Radiolabeled 75Se-silica nanoparticles: Synthesis, characterization and coating with $\omega$-functionalized alkylsilane compounds, Reactive Polymers, 25 (1995) 111-125.

[21] S.-H. Cheng, C.-H. Lee, M.-C. Chen, J.S. Souris, F.-G. Tseng, C.-S. Yang, C.-Y. Mou, C.-T. Chen, L.-W. Lo, Tri-functionalization of mesoporous silica nanoparticles for comprehensive cancer theranostics-The trio of imaging, targeting and therapy, Journal of Materials Chemistry, 20 (2010) 6149-6157.

[22] E.W. Price, C. Orvig, Matching chelators to radiometals for radiopharmaceuticals, Chemical Society Reviews, 43 (2014) 260-290.

[23] W. Owen, J. Sartor, Radiological Recovery of Land Target Components-Complex III, Naval Radiological Defense Laboratory, San Francisco, CA (1963).

[24] D. Clark Jr, W. Cobbin, Removal of Simulated Fallout from Pavements by Conventional Street Flushers, Naval Radiological Defense Laboratory, San Francisco, CA (1964). 
[25] L. Wiltshire, W. Owen, Removal of Simulated Fallout from Asphalt Streets by Firehosing Techniques, Naval Radiological Defense Laboratory, San Francisco, CA (1965).

[26] M. Kaminski, S. Landsberger, L. Nunez, G. Vandegrift, Sorption capacity of ferromagnetic microparticles coated with CMPO, Separation Science and Technology, 32 (1997) 115-126.

[27] C.Y. Jung, J.S. Kim, T.S. Chang, S.T. Kim, H.J. Lim, S.M. Koo, One-step synthesis of structurally controlled silicate particles from sodium silicates using a simple precipitation process, Langmuir, 26 (2010) 5456-5461.

[28] V. Antonovič, S. Goberis, R. Mačiulaitis, The effect of sodium silicate and its solution on the properties of refractory complex binder, Statyba, 5 (1999) 211-216.

[29] L. Zhang, H. Chen, J. Sun, J. Shen, Layer-by-layer deposition of poly (diallyldimethylammonium chloride) and sodium silicate multilayers on silica-sphere-coated substrate-Facile method to prepare a superhydrophobic surface, Chemistry of Materials, 19 (2007) 948-953.

[30] J.M. Kim, G.D. Stucky, Synthesis of highly ordered mesoporous silica materials using sodium silicate and amphiphilic block copolymers, Chemical Communications, (2000) 1159-1160.

[31] W.C. Jolin, M. Kaminski, Sorbent materials for rapid remediation of wash water during radiological event relief, Chemosphere, 162 (2016) 165-171.

[32] B. Khlebtsov, V. Khanadeev, N. Khlebtsov, Spectroturbidimetric determination of the size, concentration, and refractive index of silica nanoparticles, Optics and Spectroscopy, 105 (2008) 732-738.

[33] D.L. Perry, Handbook of Inorganic Compounds, CRC Press (2016).

[34] J.A. Rard, Chemistry and thermodynamics of europium and some of its simpler inorganic compounds and aqueous species, Chemical Reviews, 85 (1985) 555-582.

[35] S. Liu, R. Ma, Synthesis and structure of hydrated europium carbonate, Journal of Crystal Growth, 169 (1996) 190-192.

[36] Y.H. Zhao, M.H. Abraham, A.M. Zissimos, Determination of McGowan Volumes for ions and correlation with van der Waals volumes, Journal of Chemical Information and Computer Sciences, 43 (2003) 1848-1854.

[37] M. Rowles, B. O'connor, Chemical optimisation of the compressive strength of aluminosilicate geopolymers synthesised by sodium silicate activation of metakaolinite, Journal of Materials Chemistry, 13 (2003) 1161-1165. 


\section{Appendix 1: Particle Synthesis Standard Operating Procedure}

Irreversibly radiolabeling silica particles for decontamination experiments.

Standard Operating Procedure

1. Create radiolabeling solution by diluting trivalent radionuclide dissolved in $5 \mathrm{M}$ nitric acid $\left(\mathrm{HNO}_{3}\right)$ to 0.1 to $0.3 \mathrm{mCi} \mathrm{mL}^{-1}$ in deionized water (18.2 $\mathrm{M}^{\prime} \Omega$ ). The solution should be at least $10 \mu \mathrm{L}$ in volume for proper pipetting, but a volume of $50 \mu \mathrm{L}$ is recommended (enough to perform the procedure 16 times). The resulting solution should be at least $2 \mathrm{M} \mathrm{HNO}_{3}$. For example, $25 \mu \mathrm{L}$ of a deionized water can be added to a solution containing $0.4 \mathrm{mCi}^{-} \mathrm{L}^{-}$ ${ }^{1}$ of Eu-152 ( $2 \mathrm{mCi}$ in $5 \mathrm{~mL}$ ) to create a solution containing the correct concentration, while $1 \mathrm{mCi}$ of Sb-125 in $5 \mathrm{~mL}$ of $5 \mathrm{M}$ nitric acid can be used as received. If the radionuclide is dissolved into another acid (e.g., $\mathrm{HCl}$ ), the acid is to be evaporated and replaced with $5 \mathrm{M} \mathrm{HNO}_{3}$ unless a separate study had shown no adverse effect to replacing the recommended acid.

2. Obtain dry mesoporous silica either 0.5 or $2 \mu \mathrm{m}$ in diameter in powder form. The recommended supplier is Sigma Aldrich [Part \# 805890-1G (0.5 $\mu \mathrm{m})$ and 806587-1G $(2 \mu \mathrm{m})$ ]. Weigh and add $50 \mathrm{mg}$ of the silica particles to a clean, dry, and weighed $1.5-2 \mathrm{~mL}$ polypropylene centrifuge tube (Thermo Scientific catalog \#3453 recommended).

3. Add $100 \mu \mathrm{L}$ of at least $99.5 \%$ pure ethanol to the centrifuge tube containing the particles using a micropipette.

4. Centrifuge particles and ethanol for $3 \mathrm{~min}$ at $2000 \mathrm{~g}$ to ensure all particles and ethanol are at the bottom of the tube.

5. Spike $2.5 \mu \mathrm{L}$ of radiolabeling stock from Step 1 in this centrifuge tube using a micropipette. Centrifuge contents for $3 \mathrm{~min}$ at $2000 \mathrm{~g}$ (to ensure all liquid interacts with the particles).

6. Mix tube and contents on a Vortex Mixer for 5 min (e.g., setting 1 on a Fisher Scientific Vortex Mixer).

7. Sonicate tube and mixture for $15 \mathrm{~min}$ in distilled water with the tube held vertically and with at least $75 \%$ of the tube submerged in the water.

8. Place tube in sample rack within a fume hood and open tube cap. Allow contents to dry for 30-45 min. Ensure there is air flow over the tubes (otherwise, the drying time may be significantly longer than expected). Close tube.

9. Repeat steps 6-8 until no liquid is visible in the tube (generally 2-4 repetitions depending on laboratory humidity and air flow).

10. Sonicate tube for $5 \mathrm{~min}$.

11. Using a spatula transfer particles from tube to either an alumina or zirconia crucible (or other inert crucible material).

12. Place crucible with particles in a furnace.

13. Heat particles from room temperature to $750^{\circ} \mathrm{C}$ by increasing temperature $10^{\circ} \mathrm{C}$ per minute. 
14. Bake particles at $750^{\circ} \mathrm{C}$ for $1 \mathrm{~h}$.

15. Turn off oven and allow crucible and particles to cool to room temperature (generally overnight).

16. Remove crucible from oven.

17. Using a spatula and wax weighing paper to capture any loose particles, transfer the particles to a new, clean, weighed centrifuge tube (Fisher Scientific recommended).

18. Weigh particles and tube (optional - this is to permit calculating the yield of particles).

19. Spike particle with $1 \mathrm{~mL}$ of deionized water, and sonicate particles for $10 \mathrm{~min}$.

20. Mix tube with particles vigorously (Vortex Mixer, setting 10) for $1 \mathrm{~min}$ or until no particle clumps are visible.

21. Centrifuge particles at $2000 \mathrm{~g}$ for $3 \mathrm{~min}$.

22. Using a pipette, remove $750 \mu \mathrm{L}$ of the supernatant.

23. Spike particles with $750 \mu \mathrm{L}$ of new deionized water.

24. Repeat steps 20-23 twice.

25. Remove an additional $100 \mu \mathrm{L}$ of the supernatant.

26. Open the tube within a fume hood and allow to dry overnight or until no solution is visible.

27. Spike particles with $90 \mu \mathrm{L}$ of at least $99.5 \%$ pure ethanol.

28. Spike particles and ethanol with $10 \mu \mathrm{L}$ of $1 \mathrm{M}$ sodium silicate in deionized water. Centrifuge contents for $3 \mathrm{~min}$ at $2000 \mathrm{~g}$.

29. Repeat steps 6-26.

30. Once dry, particles are ready for use. Weigh and count as needed. 


\section{Appendix 2: Supplemental Information for Particle Method}

\section{Silicate Surface Coverage Calculations}

Surface coverage and depth of $\mathrm{Na}_{2} \mathrm{SiO}_{3}$ coating were determined as another means to ensure that change in particle size was minimal by the coating process. We aimed for a percent change in particle size less than $1 \%$. For clarity, this section refers to the original particle as silica and the coating as $\mathrm{SiO}_{2}$. The surface area of the silica was calculated by assuming that the particles were a perfect sphere (Table A1, Calculation \# 1-2). We then calculated the total surface area of the $50 \mathrm{mg}$ of silica added to the reactors (Calculation \# 3-9). To estimate surface coverage, the molar volume and the volume of a single molecule of $\mathrm{SiO}_{2}$ (Calculation \# 10-11) were estimated from the McGowan volume [36] of the molecule. $\mathrm{SiO}_{2}$ is the part of $\mathrm{Na}_{2} \mathrm{SiO}_{3}$ that coats the surface once heated $\left(\mathrm{Na}_{2} \mathrm{O}\right.$ is released).[37] This molecular volume was assumed to be spherical and would cover an area on the surface equal to a cross-sectional circle cut through the center of the sphere (Calculation \# 12-14). The number of cross-sectional areas needed to coat the total surface area within the sample was determined, and the moles of $\mathrm{Na}_{2} \mathrm{SiO}_{3}$ were calculated from this value (Calculation \# 15-16). The surface coverage from the number of moles of $\mathrm{Na}_{2} \mathrm{SiO}_{3}$ added to the sample was estimated (Calculation \# 17-18). This surface coverage was determined to be $1800 \%$ and $450 \%$ for $2 \mu \mathrm{m}$ and $0.5 \mu \mathrm{m}$ silica, respectively, or approximately a $180-$ and 45 -molecule thick layer of $\mathrm{SiO}_{2}$ per unit of surface area. Assuming that $\mathrm{SiO}_{2}$ would still be in spherical form, the layer thickness and subsequent change in diameter were calculated by using the diameter of the molecule (Calculation \# 19-20). We estimated that the overall change in particle diameter is $0.85 \%$ percent different from the original particles (Calculation \# 21). Therefore, we believe that the particle size is not largely changed by radiolabeling the particles, especially since the crystal $\mathrm{SiO}_{2}$ layers are likely more ordered and thinner than individual spheres. This will be confirmed with SEM imaging. 
Table A1. Parameters and results from the calculation of $\mathrm{SiO}_{2}$ layer thickness, including values, units, and assumptions

\begin{tabular}{|c|c|c|c|c|c|}
\hline Calculation \# & Parameter & $\begin{array}{c}\text { Value for } 2 \mu \mathrm{m} \\
\text { particles }\end{array}$ & $\begin{array}{l}\text { Value for } 0.5 \\
\mu \mathrm{m} \text { particles }\end{array}$ & Units & Assumptions/Notes \\
\hline 1 & Diameter of Silica Particles & 2 & 0.5 & $\mu \mathrm{m}$ & All particles are same size \\
\hline 2 & Surface Area of Silica Particles & 12.57 & 0.79 & $\mu \mathrm{m}^{2} /$ particle & Particles are perfect spheres \\
\hline 3 & Density & 2.65 & 2.65 & $\mathrm{~g} / \mathrm{cm}^{3}$ & Density of $\mathrm{SiO}_{2}$ \\
\hline 4 & Density & $2.65 \times 10^{-12}$ & $2.65 \times 10^{-12}$ & $\mathrm{~g} / \mu \mathrm{m}^{3}$ & Density of $\mathrm{SiO}_{2}$ \\
\hline 5 & Particle Volume & 4.19 & 0.07 & $\mu \mathrm{m}^{3}$ & Particles are perfect spheres \\
\hline 6 & Particle Weight & $1.11 \times 10^{-8}$ & $1.73 \times 10^{-10}$ & $\mathrm{mg} /$ particle & \\
\hline 7 & Mass of particles in sample & 50 & 50 & $\mathrm{mg}$ & \\
\hline 8 & Number of particles in sample & $4.50 \times 10^{9}$ & $2.88 \times 10^{11}$ & particles & Particles are homogenous \\
\hline 9 & Total surface area of particles in sample & $5.66 \times 10^{10}$ & $2.26 \times 10^{11}$ & $\mu \mathrm{m}^{2}$ & \\
\hline 10 & Volume of $\mathrm{SiO}_{2}$ & 31.98 & 31.98 & $\mathrm{~cm}^{3} / \mathrm{mole}$ & $\begin{array}{l}\text { Estimated from McGowan molar } \\
\text { volume[36] }\end{array}$ \\
\hline 11 & Volume of $\mathrm{SiO}_{2}$ & $5.31 \times 10^{-23}$ & $5.31 \times 10^{-23}$ & $\mathrm{~cm}^{3} /$ molecule & \\
\hline 12 & Radius of $\mathrm{SiO}_{2}$ & $2.33 \times 10^{-8}$ & $2.33 \times 10^{-8}$ & $\mathrm{~cm}$ & (23 angstroms) \\
\hline 13 & Area $\mathrm{SiO}_{2}$ Sphere & $1.71 \times 10^{-15}$ & $1.71 \times 10^{-15}$ & $\mathrm{~cm}^{2} /$ molecule & $\begin{array}{l}\text { Circle cut through the center point of the } \\
\text { sphere }\end{array}$ \\
\hline 14 & Area $\mathrm{SiO}_{2}$ Sphere & $1.71 \times 10^{-7}$ & $1.71 \times 10^{-7}$ & $\mu \mathrm{m}^{2} /$ molecule & $\begin{array}{l}\text { Circle cut through the center point of the } \\
\text { sphere }\end{array}$ \\
\hline 15 & Circles to cover surface area & $3.31 \times 10^{17}$ & $1.33 \times 10^{18}$ & molecules & \\
\hline 16 & $\begin{array}{c}\text { Moles } \mathrm{Na}_{2} \mathrm{SiO}_{3} \text { needed to create monolayer } \\
\text { across surface }\end{array}$ & $5.50 \times 10^{-7}$ & $2.20 \times 10^{-6}$ & moles & \\
\hline 17 & Moles $\mathrm{Na}_{2} \mathrm{SiO}_{3}$ added to sample & 0.00001 & 0.00001 & moles & \\
\hline 18 & Surface Coverage & 1817 & 454 & $\%$ & \\
\hline 19 & Layer Thickness & 0.008 & 0.002 & $\mu \mathrm{m}$ & Thickness of $\mathrm{SiO}_{3}$ Layer \\
\hline 20 & Change in diameter & 0.017 & 0.004 & $\mu \mathrm{m}$ & \\
\hline 21 & Percent Change in Depth & 0.84747 & 0.84747 & $\%$ & \\
\hline
\end{tabular}




\section{Additional SEM Images}

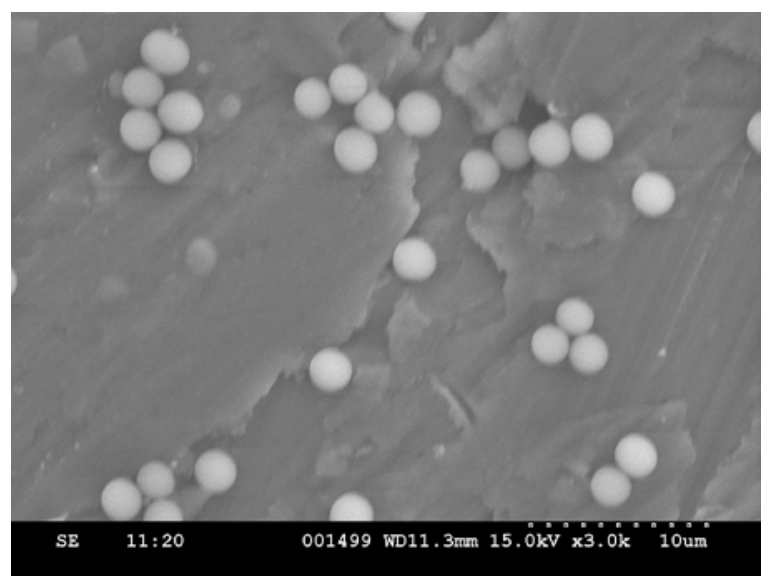

Figure A1: SEM image of $2 \mu \mathrm{m}$ particles coated in $\mathrm{Na}_{2} \mathrm{SiO}_{3}$ and baked at $500^{\circ} \mathrm{C}$

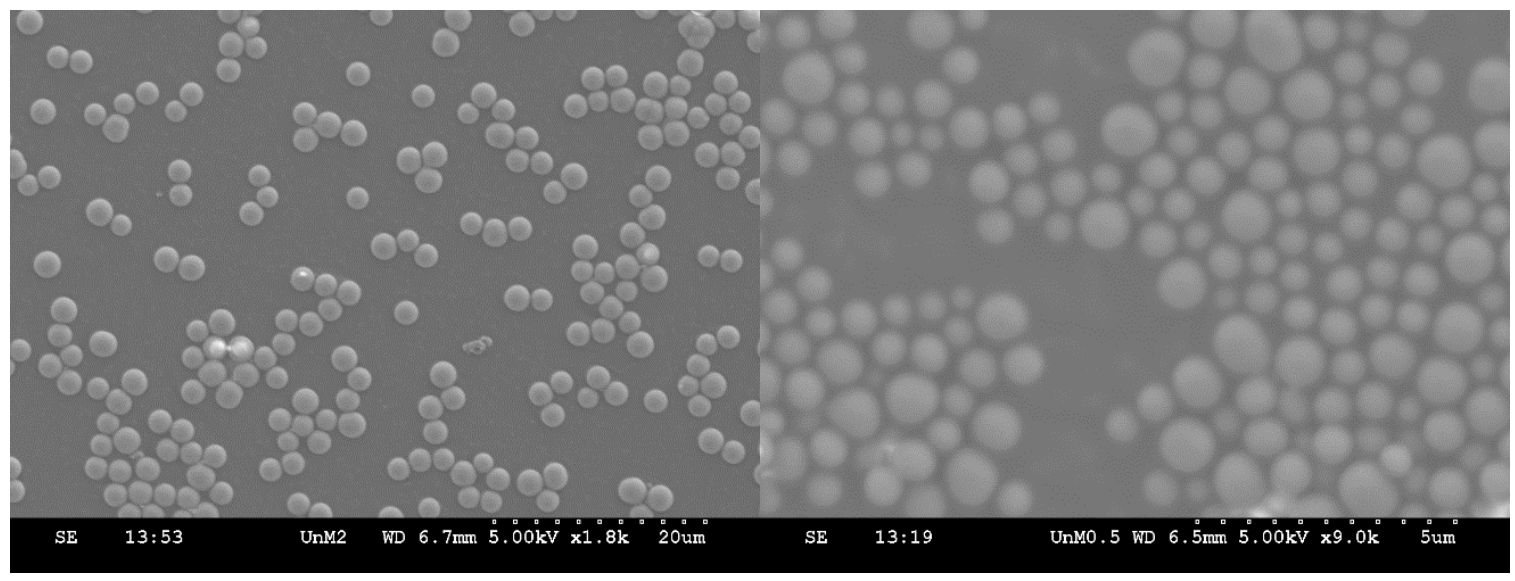

Figure A2: SEM image of unmodified $2 \mu \mathrm{m}$ (left) and $0.5 \mu \mathrm{m}$ (right).

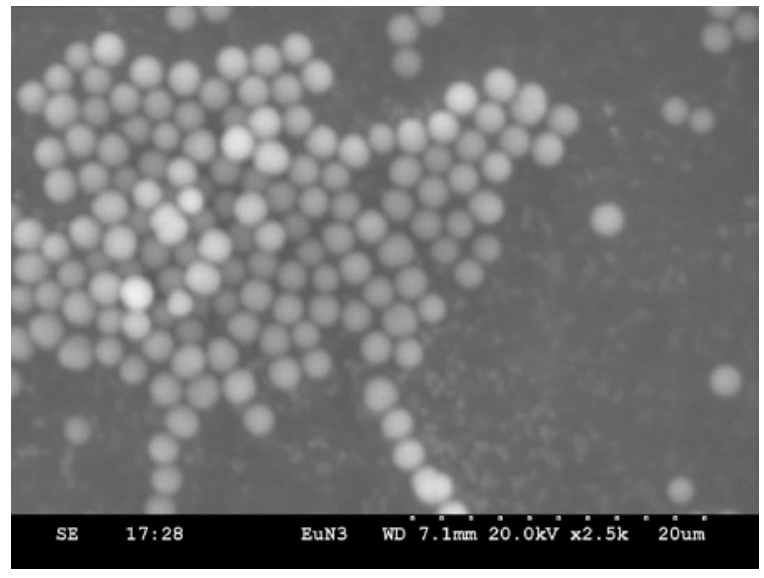

Figure A3: SEM image of $2 \mu \mathrm{m}$ particles only spiked with $\mathrm{Eu}\left(\mathrm{NO}_{3}\right)_{3}$ and baked at $750^{\circ} \mathrm{C}$ 


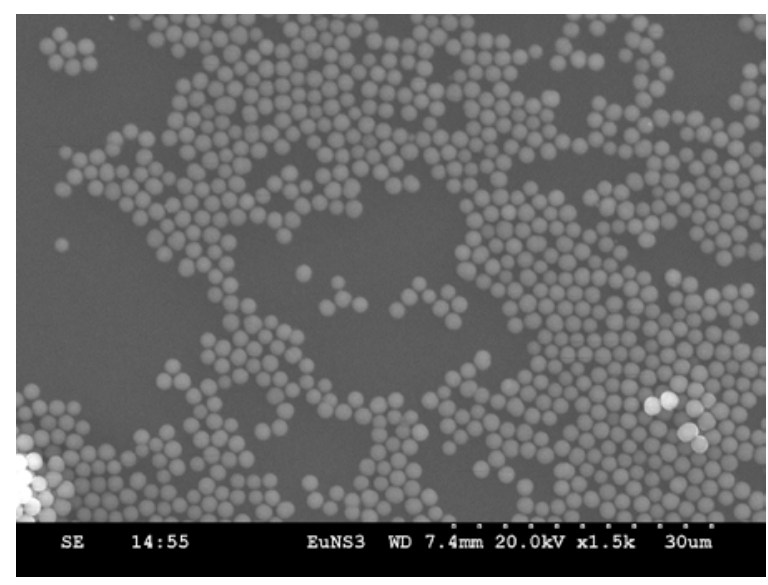

Figure A4: SEM image of $2 \mu \mathrm{m}$ spiked with $\mathrm{Eu}\left(\mathrm{NO}_{3}\right)_{3}$ and heated to $750^{\circ} \mathrm{C}$, then coated with $\mathrm{Na}_{2} \mathrm{SiO}_{3}$ without washing in between steps. 
Appendix 3: Visual Log of Cesium Removals

3-A: Initial contamination of tire (top left), acrylic (top right), low gloss paint (bottom left), and high gloss paint (bottom right) coupons
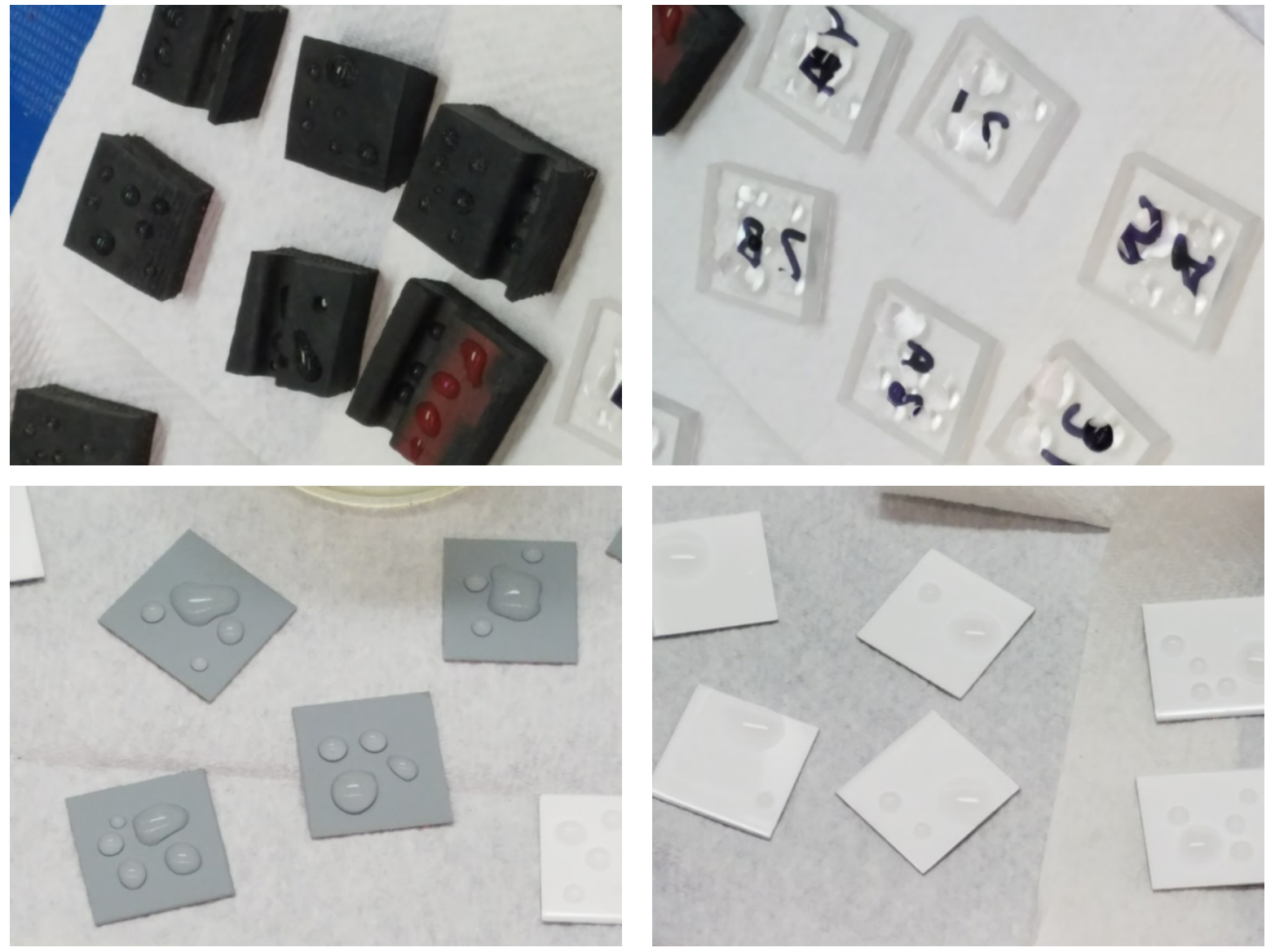
3-B: Coupons after 1 hour of drying
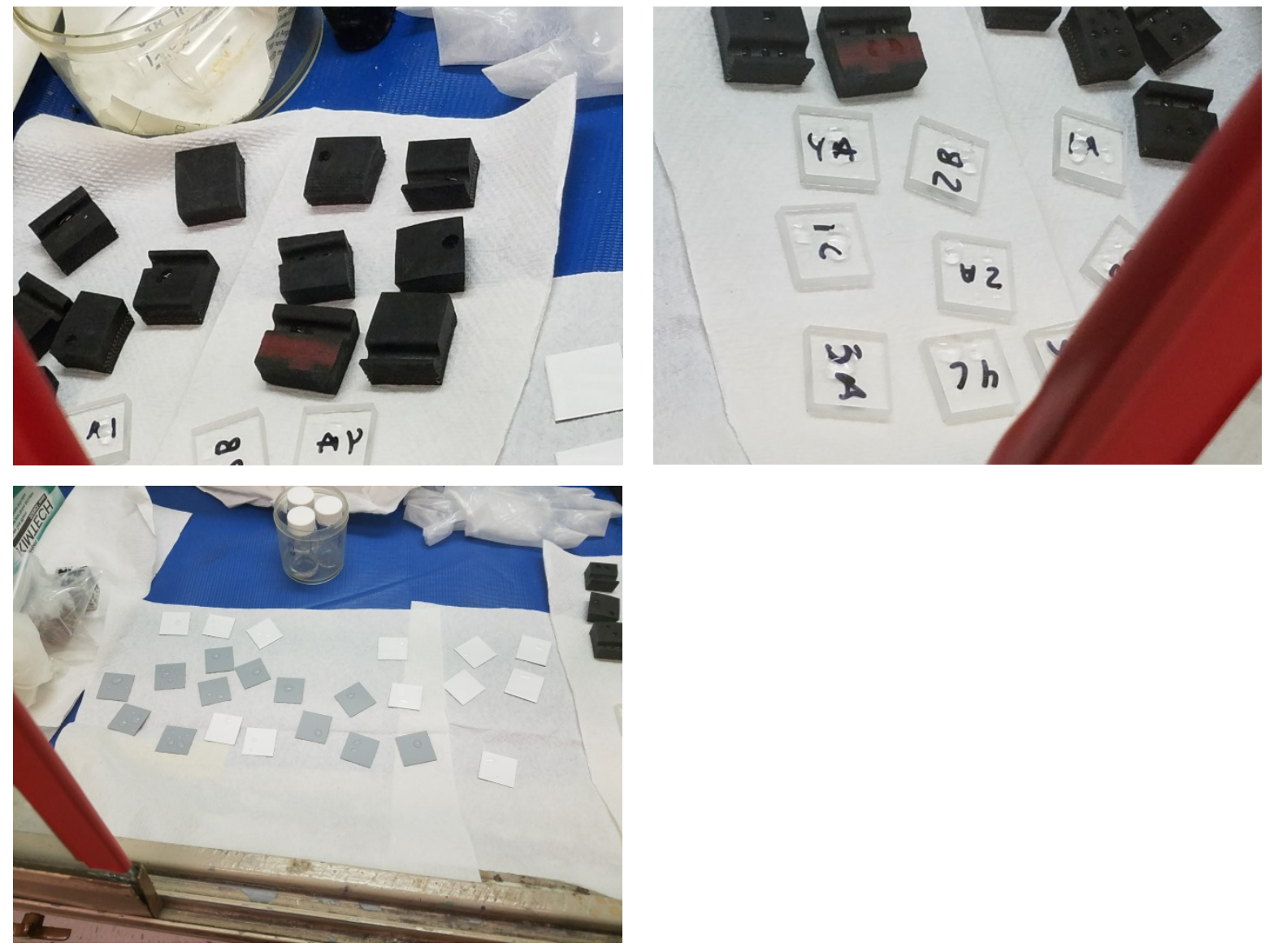
3-C: Coupons after 1.5 hours of drying
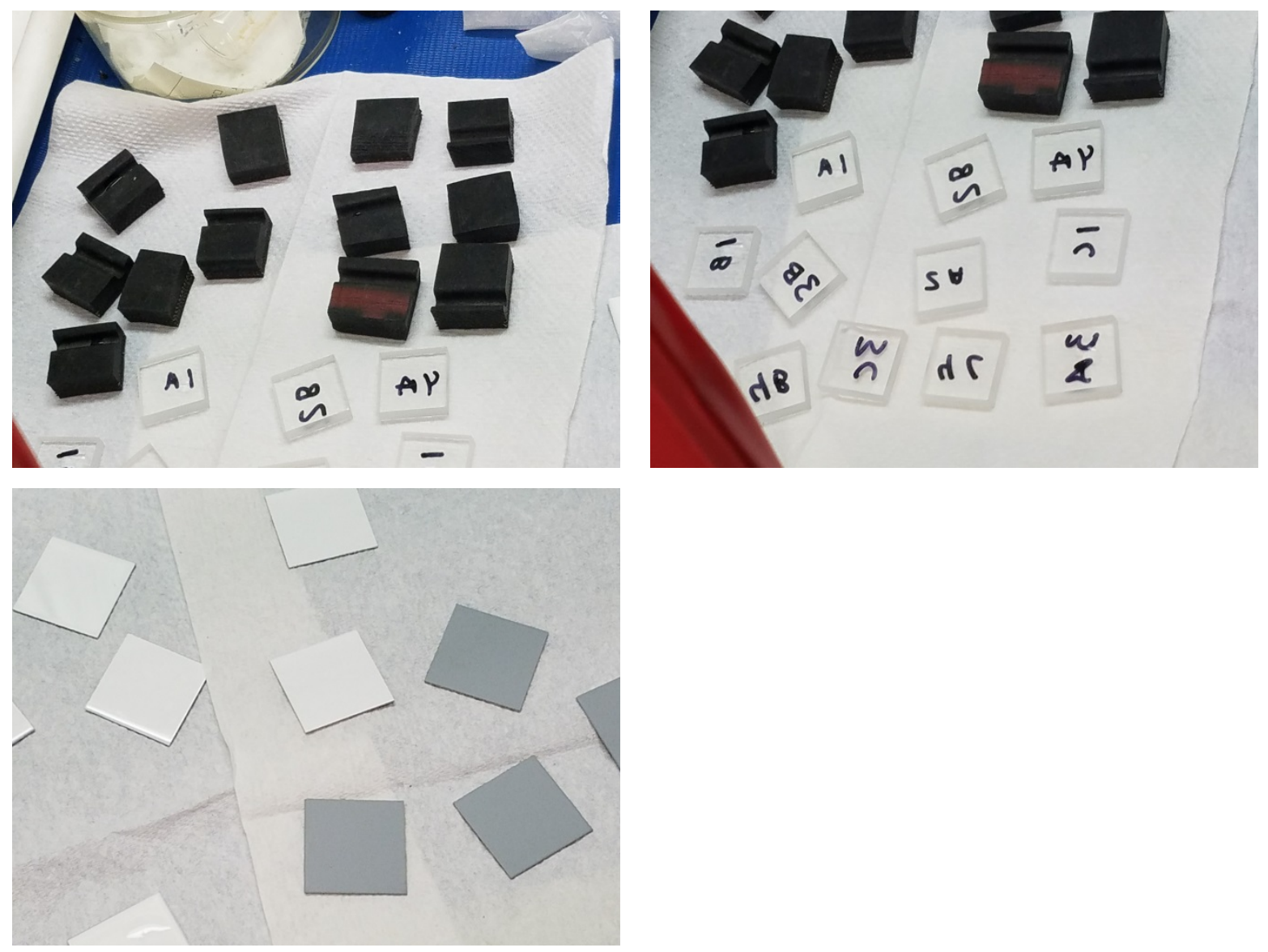
3-D: Fully dry coupons, 2 hours after exposure
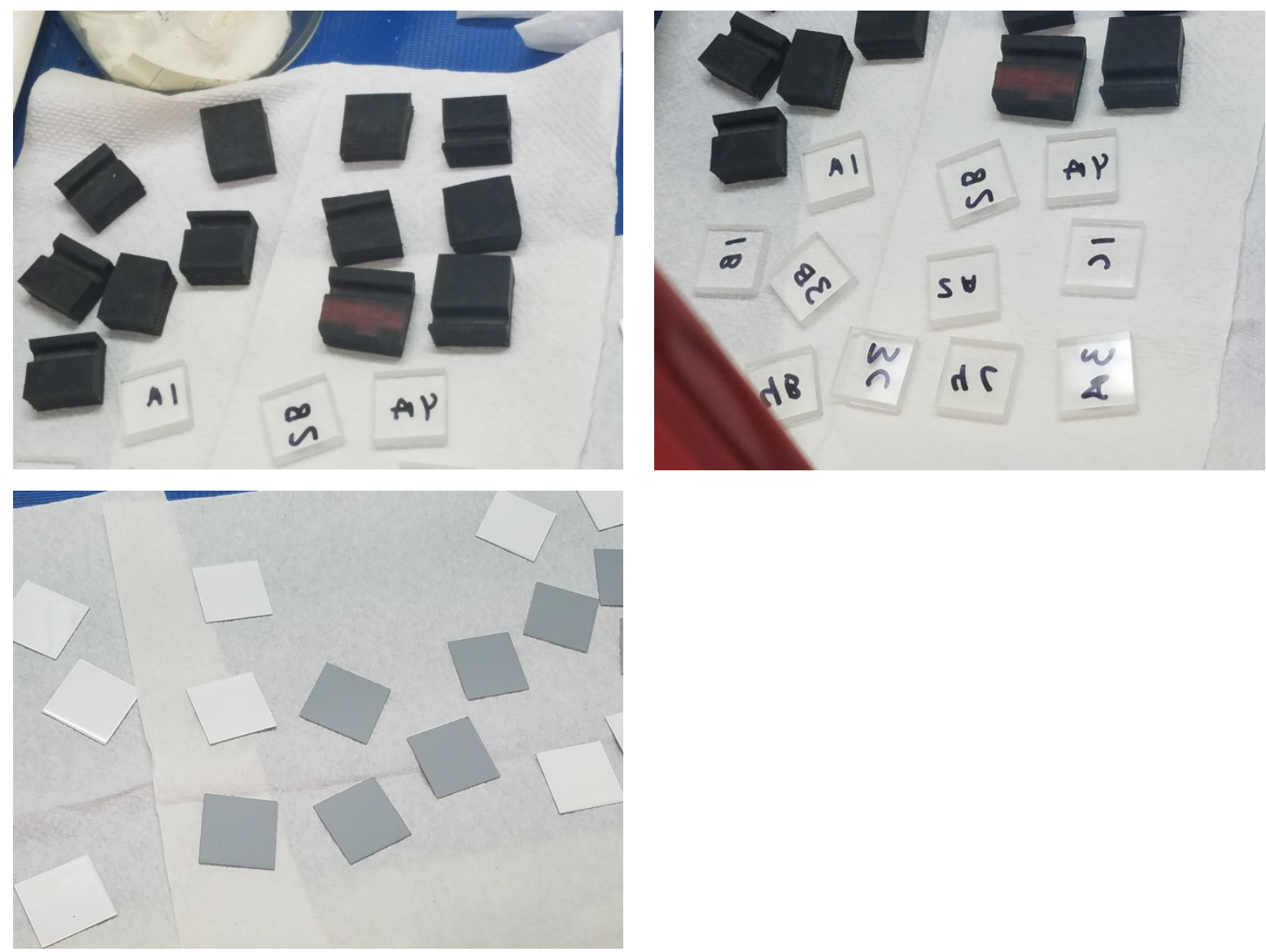
3-E: Application of DeconGel
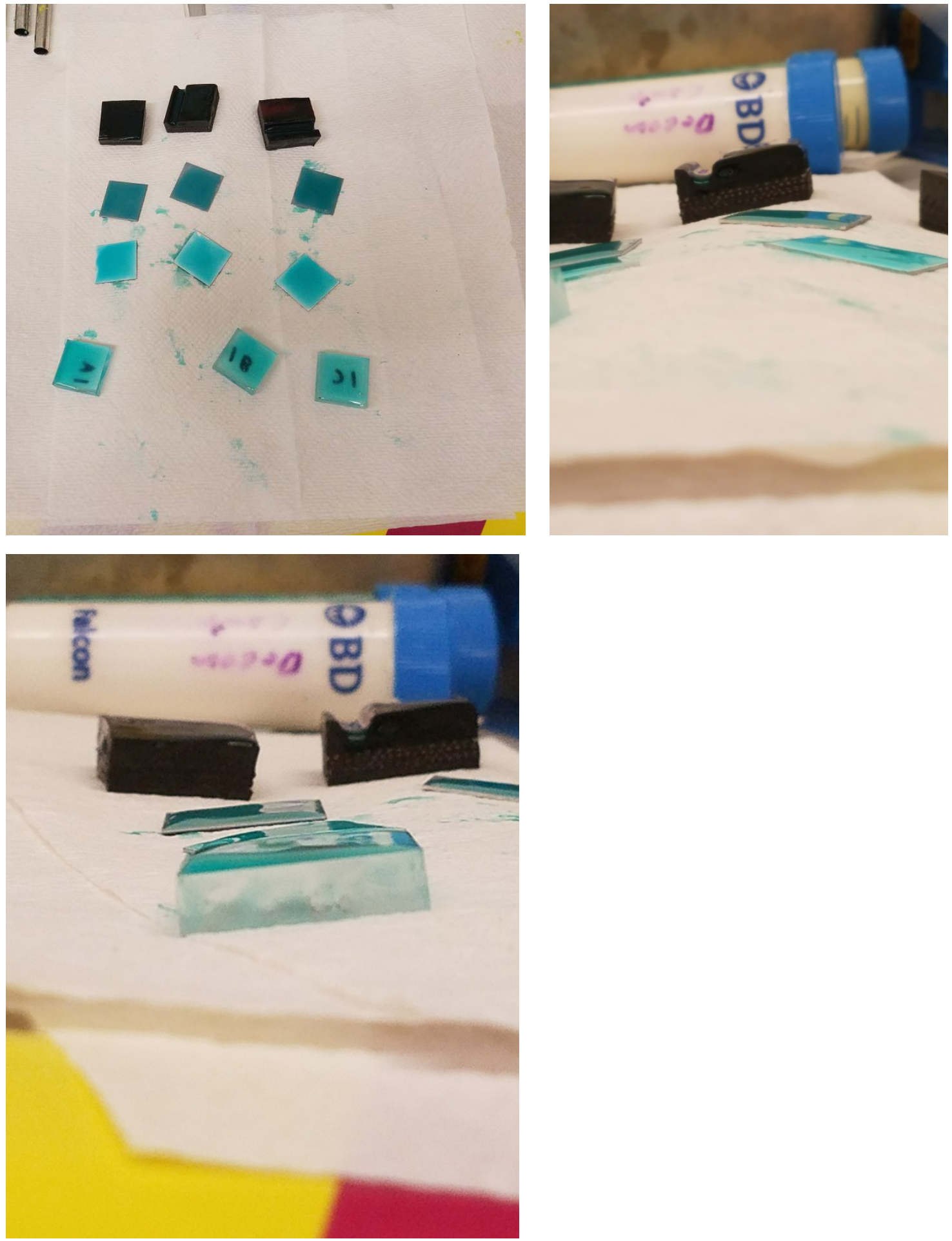
3-F: Application of StripCoat
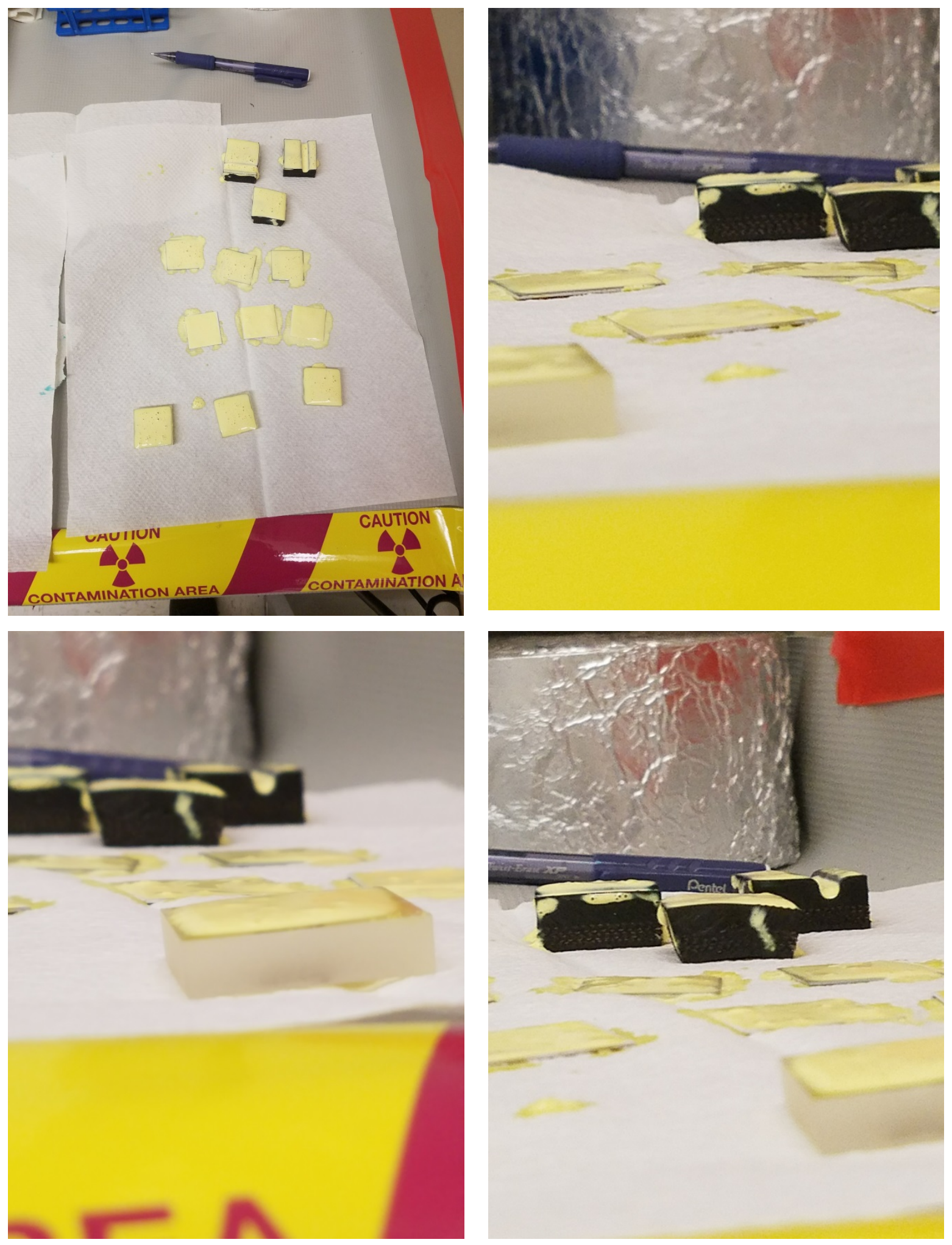
3-G: Application of DeconCoat
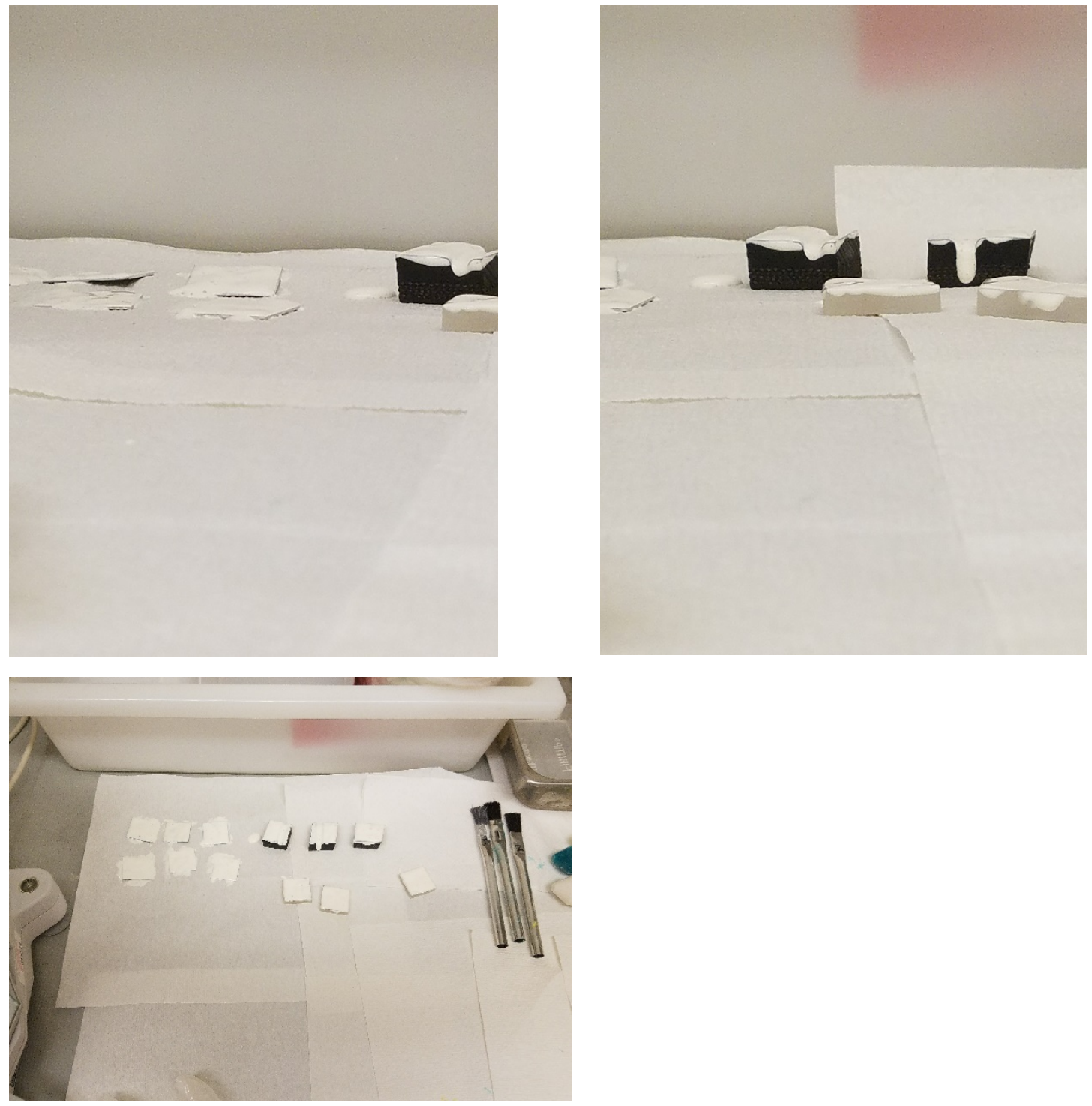
3-H: Application of SprayLat
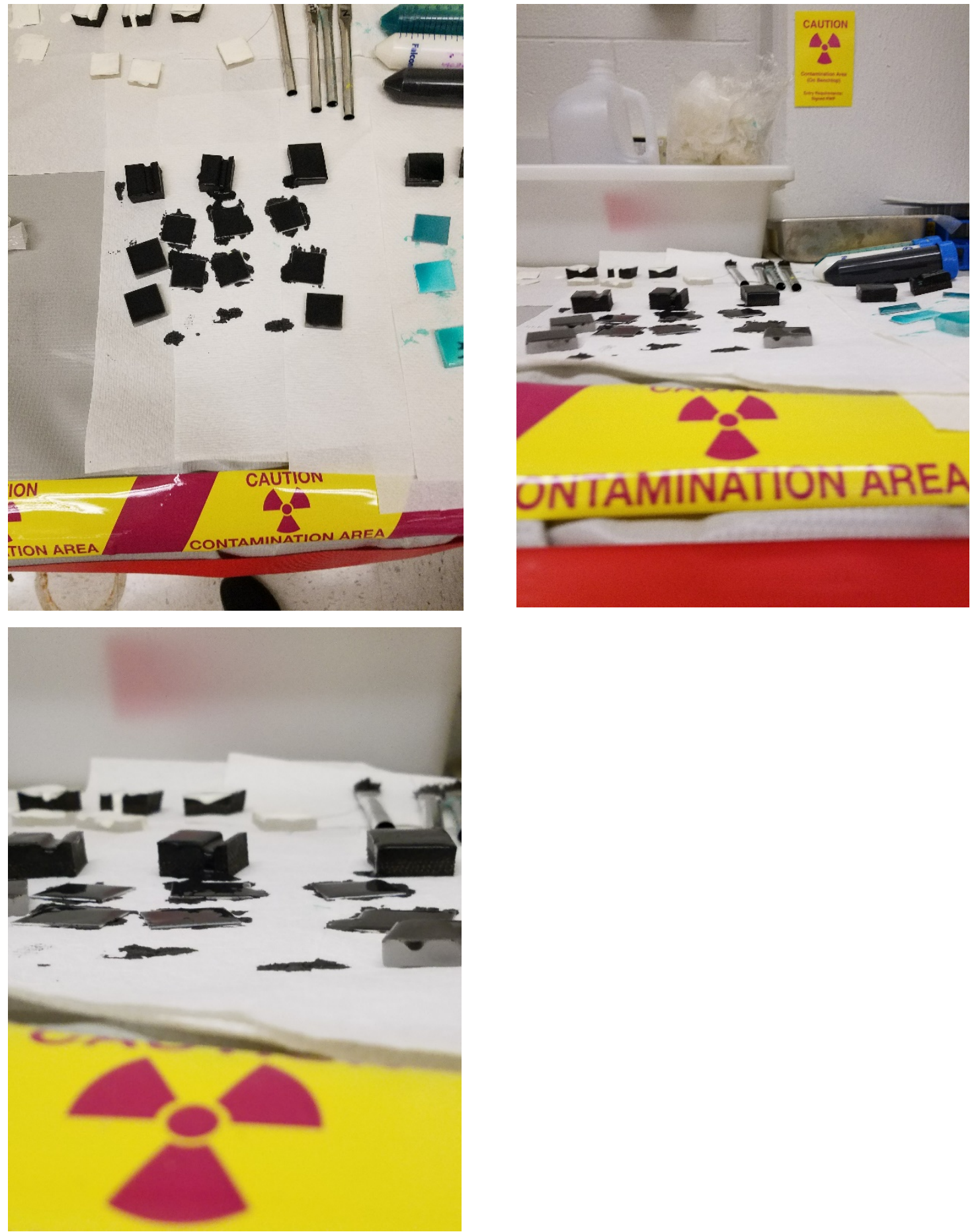
3-I: Each method after 2 hours of drying: DeconGel (top left) StripCoat (top right), DeconCoat (bottom left), SprayLat (bottom right).
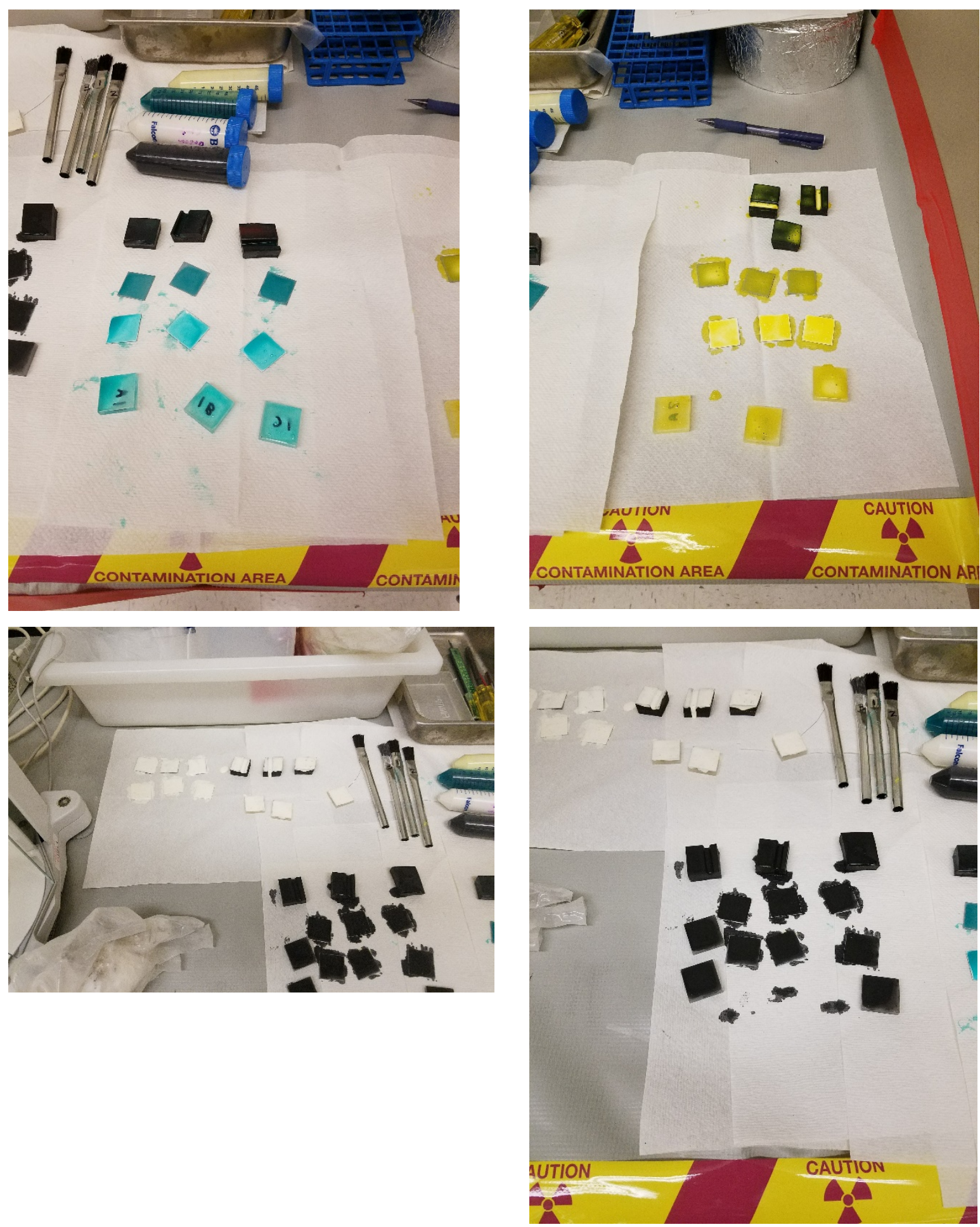
3-J: Agents fully dry: DeconGel (top left), StripCoat (top right), DeconCoat (bottom left), SprayLat (bottom right).
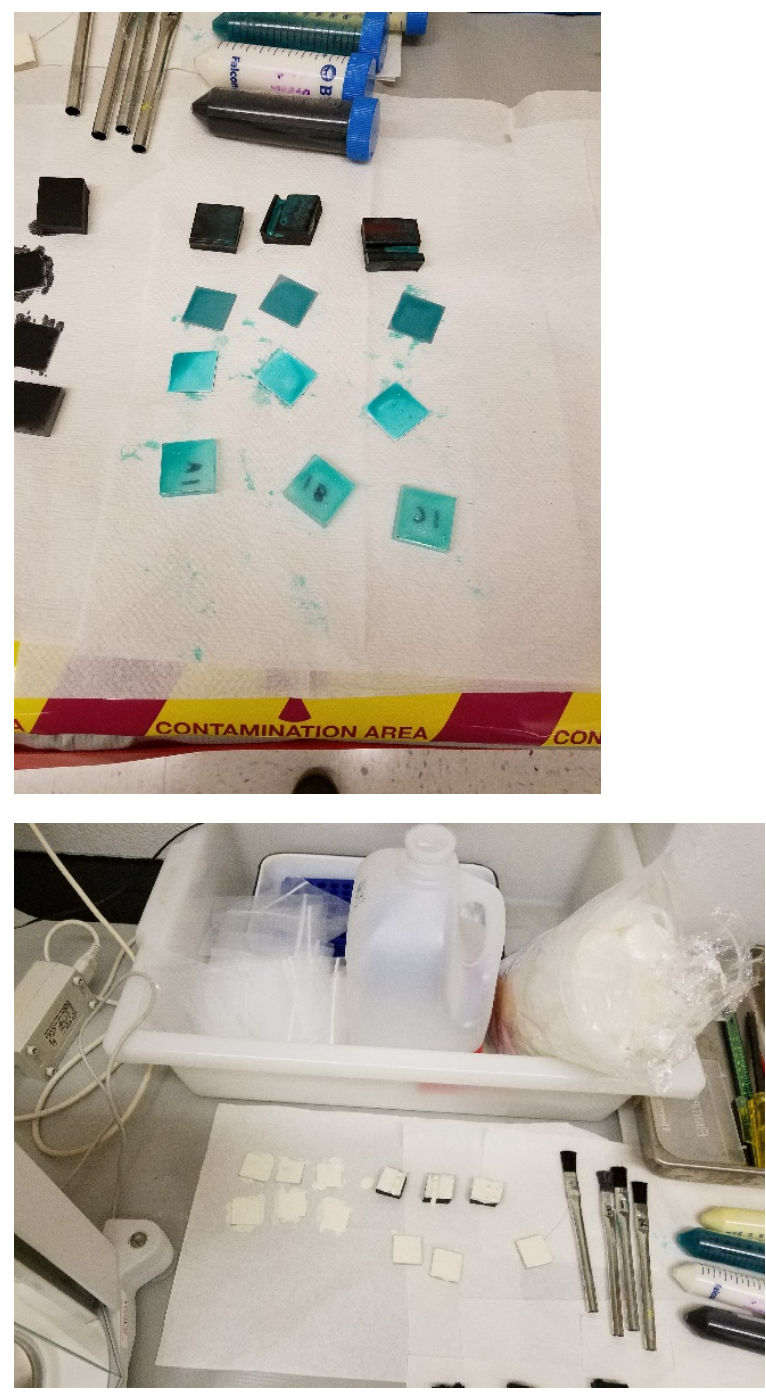
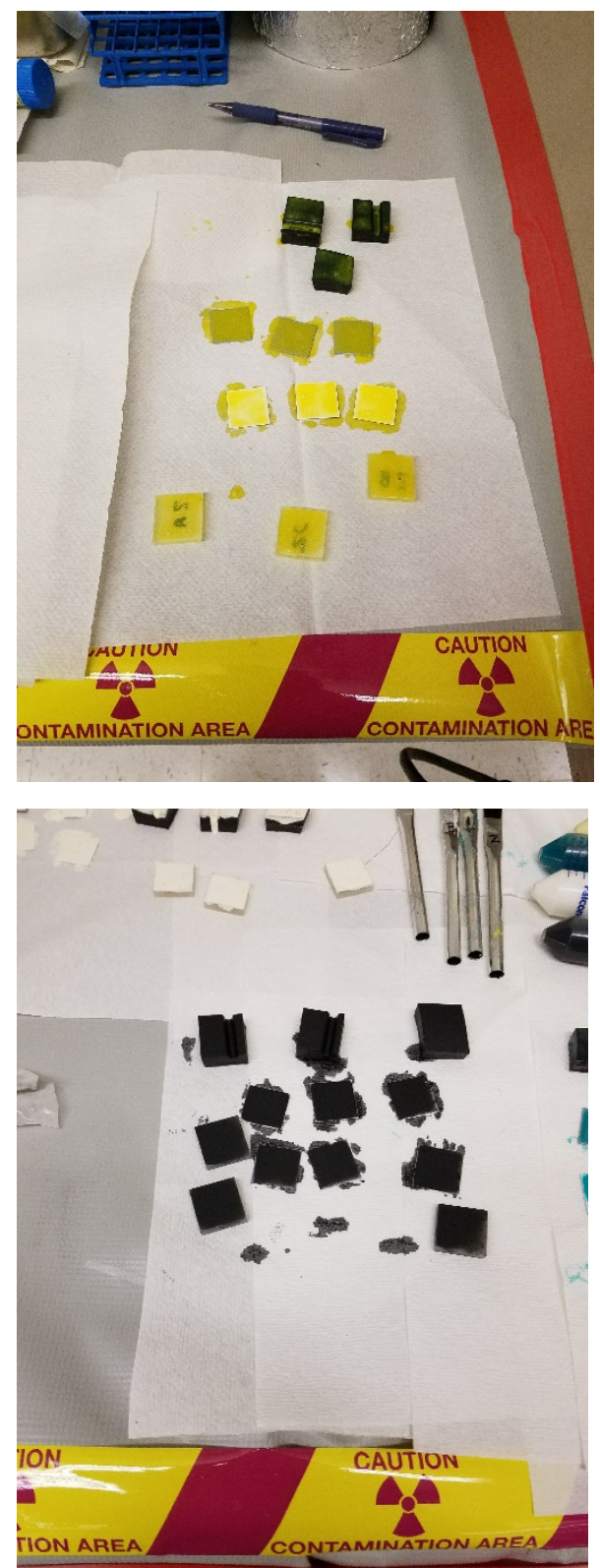
3-K: Side view of dried coupons with films - DeconGel (top left), StripCoat (top right), DeconCoat (bottom left), SprayLat (bottom right).
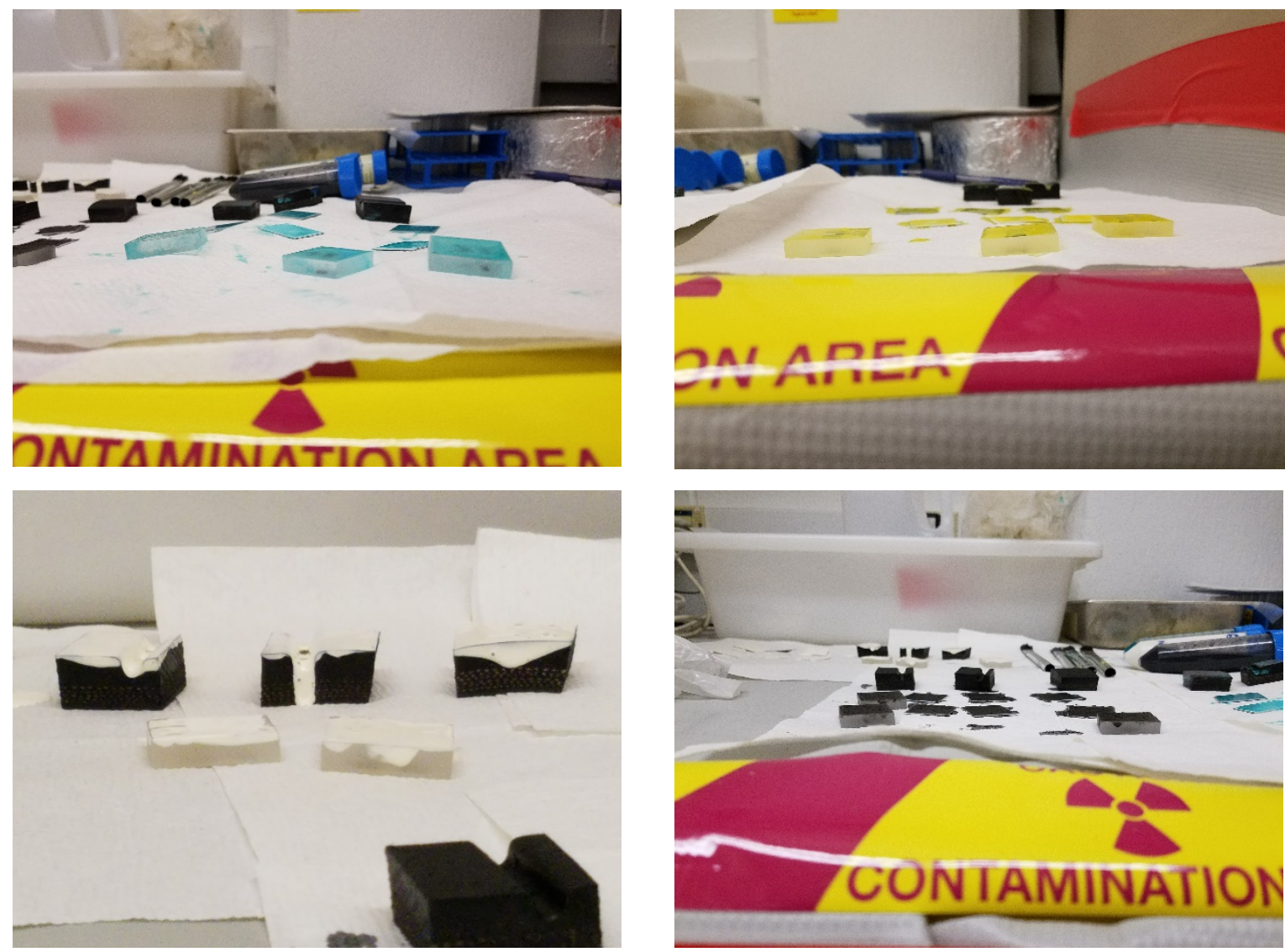
3-L: Coupons during peeling process - DeconGel (top left), StripCoat (top right), DeconCoat (bottom left), SprayLat (bottom right).
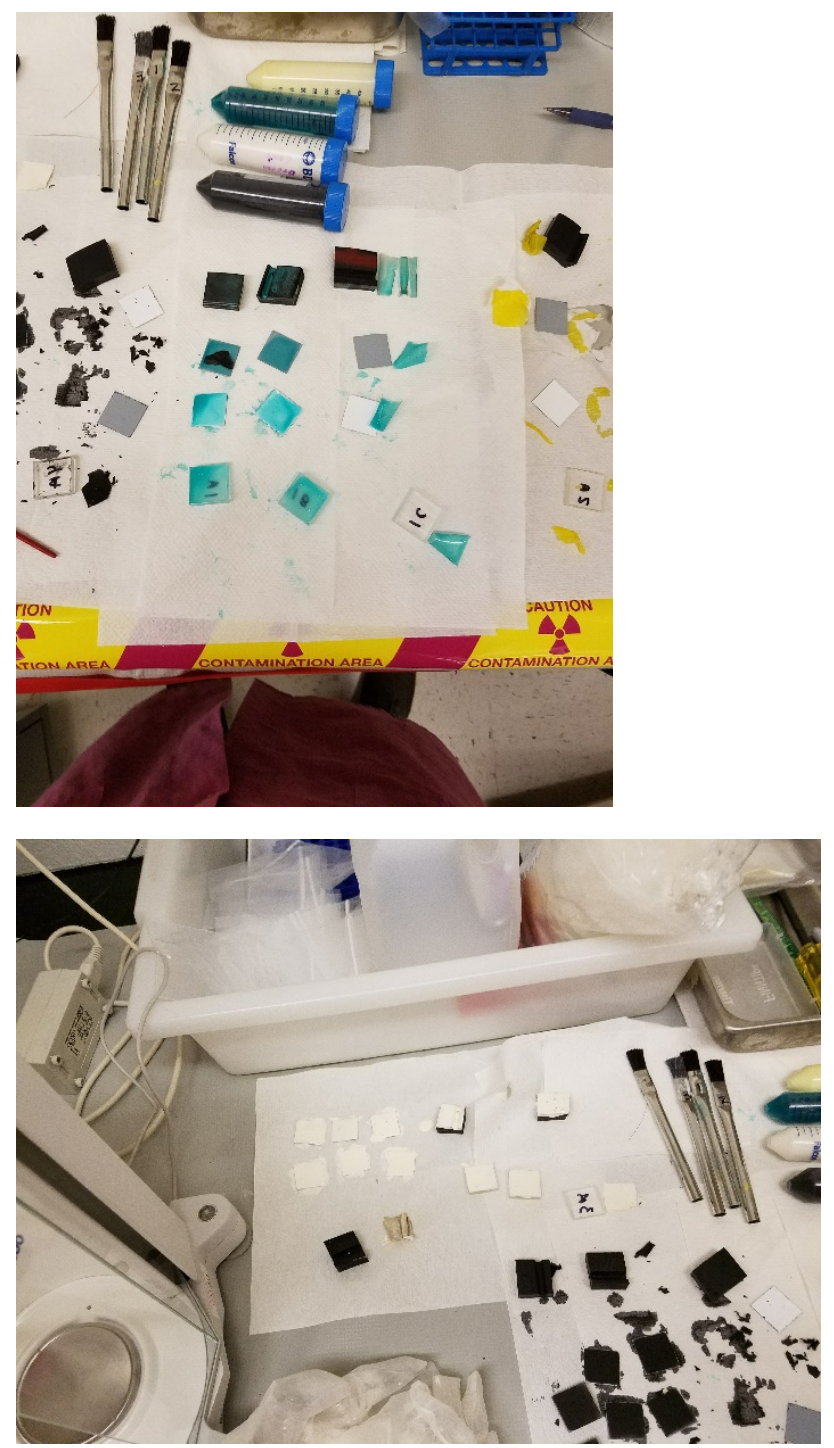
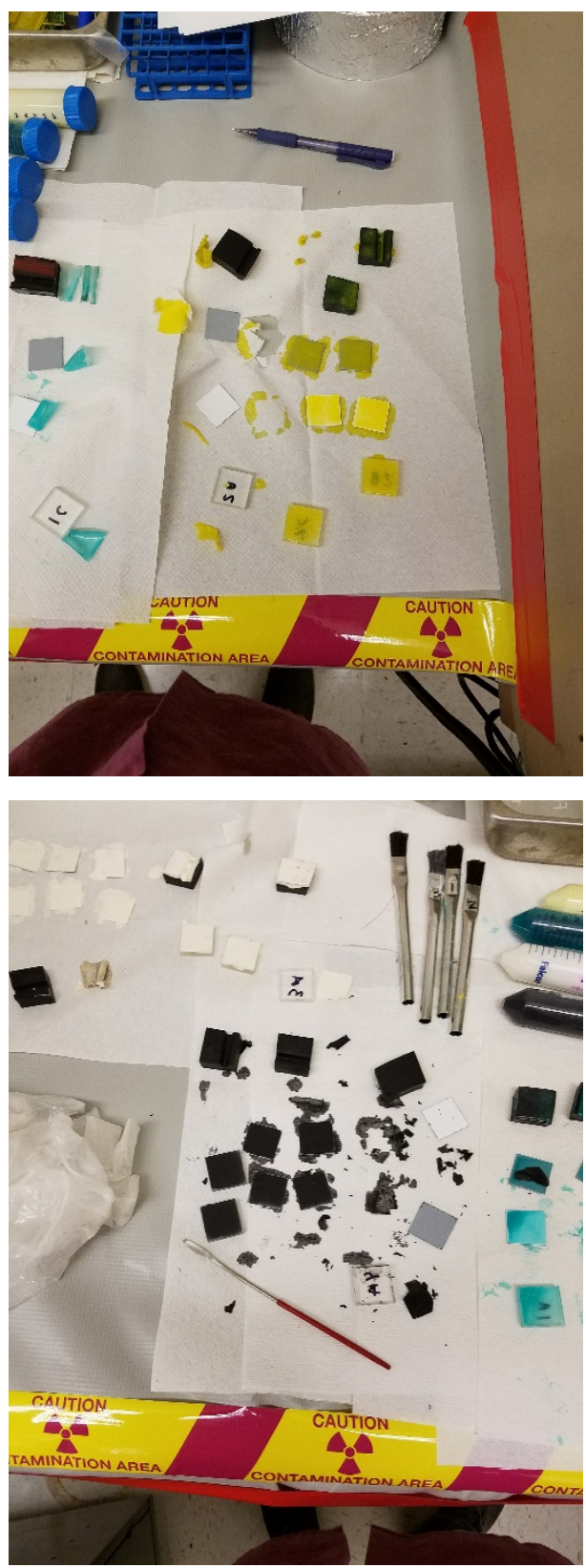
3-M: Damage to W-4A after initial removal (scrapped with spatula)

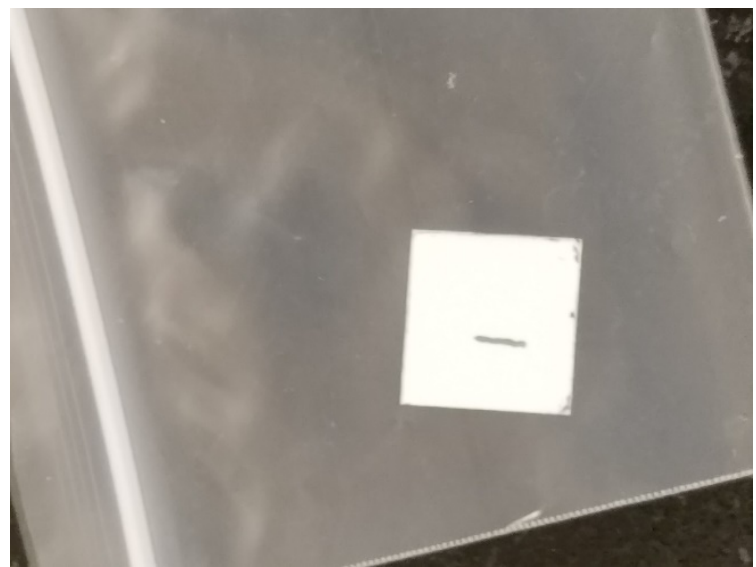


3-N: Damage to coupons after entire experimental process of note: chips for white painted coupons (high gloss) for DeconCoat and StripCoat. DeconGel (top left), StripCoat (top right), DeconCoat (bottom left), SprayLat (bottom right).
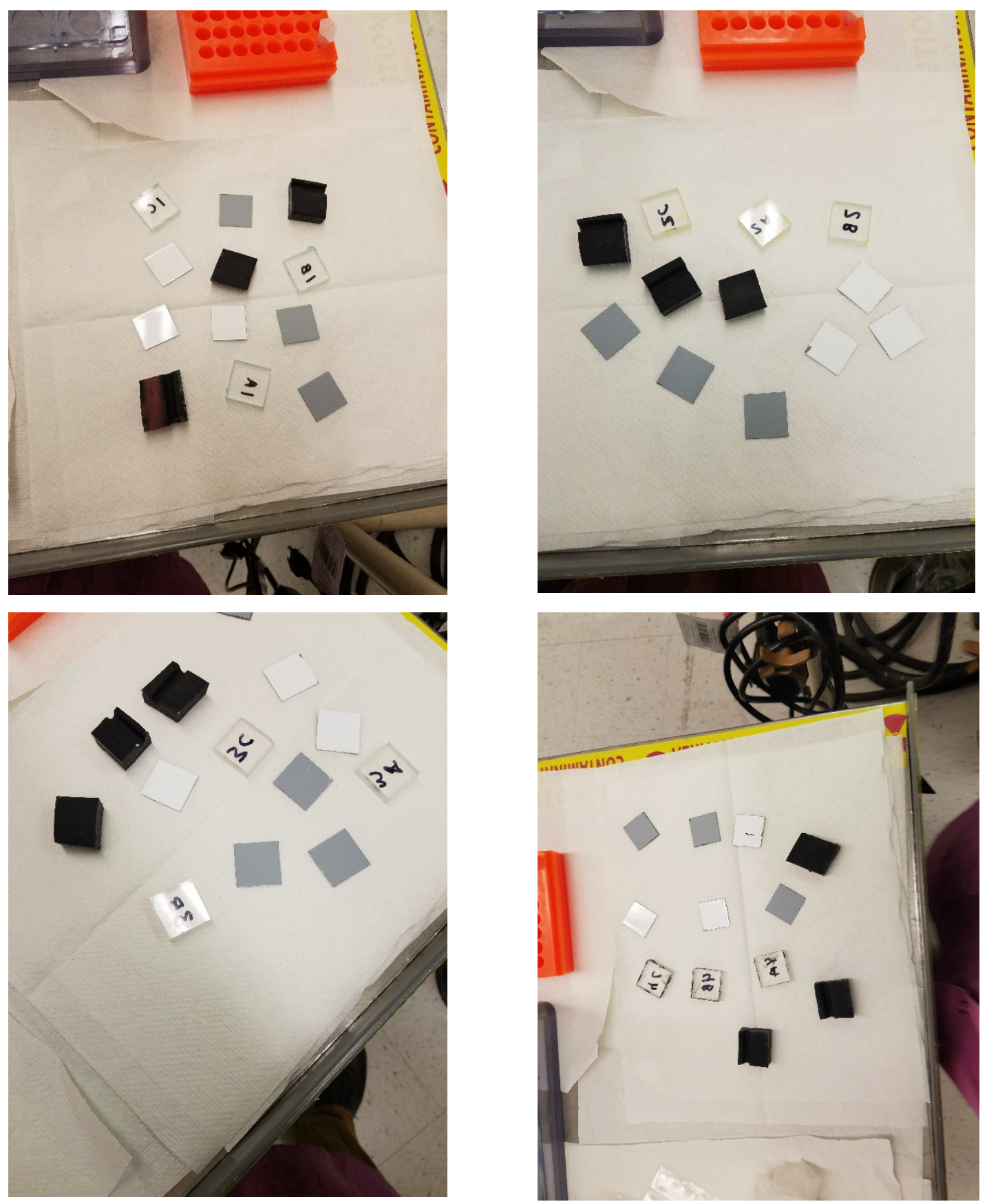
$54 \mid \mathrm{P}$ ag e 



\section{Argonne}

Strategic Security Sciences Division

Argonne National Laboratory

9700 South Cass Avenue, Bldg. 205

Argonne, IL 60439-4854

www.anl.gov

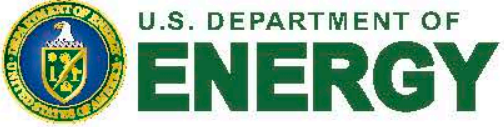

Argonne National Laboratory is a U.S. Department of Energy

laboratory managed by UChicago Argonne, LLC 